\title{
Uso de nutrientes tecnológicos como materia prima en la fabricación de materiales de construcción en el paradigma de la economía circular
}

\author{
Use of technological nutrients as source for building materials manufacturing in the \\ circular economy paradigm
}

\section{Uso de nutrientes tecnológicos como matéria-prima para a fabricação de materiais de construção dentro do modelo de economia circular}

\author{
Alejandra Sarabia-Guarin ${ }^{1}$, Jorge Sánchez-Molina², Juan Carlos Leyva-Díaz
}

Forma de citar: A. Sarabia-Guarin, J. Sánchez-Molina y J.C. Leyva-Díaz "Uso de nutrientes tecnológicos como materia prima en la fabricación de materiales de construcción en el paradigma de la economía circular", Respuestas, vol. 22, no. 1, pp. 6-16, 2017.

Recibido:

Julio 29 de 2016

Aceptado:

Noviembre 1 de 2016

\section{Resumen}

Antecedentes: El sector de la construcción es uno de los sectores económicos en Colombia con mayor crecimiento, generando grandes cantidades de residuos como producto del proceso de construcción, y/o demolición, o en su defecto en la fabricación de los materiales de construcción. Objetivo: facilitar el acceso a información académicocientífica actualizada sobre reciclaje de residuos industriales y su aplicación en la fabricación de materiales de construcción. Así mismo se emplea el término de economía circular, el cual hace referencia a la integración de las actividades de reducción (consumo de energía y residuos), reutilización y recuperación durante la producción, el intercambio y consumo. Conclusión: además de reducir la contaminación generada por los residuos de los sectores productivos, con el aprovechamiento de los subproductos ha sido posible mejorar ciertas propiedades tecnológicas de estos materiales de construcción.

Palabras Clave: Economía circular, materiales de construcción, nutriente tecnológico, reciclaje, residuos industriales.

\begin{abstract}
Background: The construction sector is one of the economic sectors with the highest growth in Colombia, generating large amounts of waste as a result of the construction process, and / or demolition, as well as in the building material manufacturing. Objective: to facilitate the access to updated academic-scientific information about recycling of industrial waste and its application in building material manufacturing. Moreover, the concept of circular economy is used, which refers to the integration of the reduction activities (energy consumption and waste), reuse and recovery during the production, exchange and consumption. Conclusion: in addition to the reduction of the pollution generated by waste from the productive sectors, improvement of certain technological properties of these building materials has been obtained through the use of waste.
\end{abstract}

Keywords: Circular economy, building materials, technological nutrient, recycling, industrial waste. 


\section{Resumo}

Antecedentes: Na Colômbia, o sector da construção é um dos setores económicos com maior crescimento, gerando grandes quantidades de resíduos como produto do processo de construção, e/ou demolição, ou falha na fabricação dos materiais de construção. Objetivo: facilitar o acesso à informação académico-científica atualizada sobre reciclagem de resíduos industriais e sua aplicação na fabricação de materiais de construção. Da mesma forma, foi empregado o termo de economia circular, o qual faz referência à integração das atividades de redução (consumo de energia e resíduos), reutilização e recuperação durante a produção, a troca e consumo. Conclusão: além de reduzir a contaminação gerada pelos resíduos dos setores produtivos, com o aproveitamento dos subprodutos tem sido possível melhorar certas propriedades tecnológicas destes materiais de construção.

Palavras-chave: Economia circular, materiais de construção, nutriente tecnológico, reciclagem, resíduos industriais.

\section{Introducción}

Los sectores característicos de la economía colombiana son el agroindustrial, servicios y manufacturas. Dentro de este último, se encuentra el sector de la construcción, el cual ha crecido en promedio cerca del $8 \%$ en los últimos cinco años como resultado de diversos programas de vivienda y proyectos de infraestructura impulsados por el Gobierno Nacional, teniendo como resultado la tercera inversión mas grande en América Latina para 2014. Dicho sector ha concentrado su demanda de productos en tres grupos: productos minerales no metálicos (vidrio, productos de hormigón, cemento y yeso, artículos de cerámica no estructural, ladrillo, losas y adoquines), productos metalúrgicos básicos (laminados de hierro o acero y productos metálicos estructurales) y minerales no metálicos (piedra común, mármol, granito, arenas de peña y rio, grava, gravilla) [1], contribuyendo de un modo u otro a la generación de residuos, ya sea por la producción de materiales de construcción o como resultado de la demolición y construcción [2].
La eliminación de estos y otros residuos es una de las problemáticas medioambientales actuales, y se ha convertido en una de las principales preocupaciones en los países industrializados, provocando interés en la generación de soluciones por parte de la ciudadanía, el sector público y el sector productivo [3]. Todo lo anterior está configurando un nuevo escenario donde los distintos sectores productivos deben de ir adoptando medidas para que se vayan posicionando bajo el paradigma de la economía circular, donde se establecen plazos para que dichos sectores productivos reduzcan tanto emisiones de gases de efecto invernadero como eliminación de residuos. En este sentido, la economía circular va a ser una realidad cada día más presente, lo que conlleva que los sectores productivos deben de plantearse que la conservación del medio ambiente y la escasez de recursos productivos y energéticos deben de ser tenidos en cuenta [4]. ISSN 0122-820X -ISSN 2422-5053

Entre otras soluciones, varios autores han planteado que creando plantas de 
transformación y zonas especiales de almacenamiento en lugares aislados [5], [6], los residuos de construcción y demolición (RCD), como el hormigón, agregado, poliestireno, cenizas volantes, escorias de hornos, asfalto, maderas, yeso, ladrillos, metal, vidrio, lodos, e incluso aguas de lavado de los equipos de amasado y bombeo del hormigón [7], podrían ser recirculados y usados como aditivos para la fabricación de nuevos productos en lugar de usar materias primas naturales [6], [8]. Castells [9], [10] ha planteado diversas soluciones en el proceso de fabricación de los materiales de construcción, así como de los productos de los cuales muchos están formados, estudios que incluyen cambios en la extracción de los recursos naturales necesarios para su elaboración, en el proceso de fabricación y en el consumo de energía.

En la actualidad, el hecho de que el crecimiento del sector de la construcción a nivel mundial demande más cantidades de materias primas que cualquier otra actividad económica incluyendo materiales no renovables, (cerca de $3000 \mathrm{Tm} /$ año, casi el 50\% en peso) [11], genere residuos que afectan negativamente al medio ambiente, y sea responsable del $30 \%$ de las emisiones de $\mathrm{CO}_{2}$ [12], se ha convertido en un reto que tanto la comunidad como el sector público y privado ha buscado resolver [3], con el planteamiento de acciones inmediatas y tecnologías alternativas, limpias e innovadoras encaminadas a la recuperación y reutilización, que responda a la crisis ambiental global que se vislumbró desde la década de 1970 [13], sin afectar la calidad y/o el objeto de uso del propio producto. El diseño y fabricación de nuevos materiales, especialmente el cemento y los cerámicos, los cuales tienen mayor demanda en el sector de la construcción [9], [14], es una alternativa sostenible para los materiales de desecho [15].

Finalmente con esta revisión se pretende permitir el acceso a información académico- científica actualizada de los resultados de investigación sobre recuperación de residuos industriales y su aplicación en la fabricación de materiales de construcción; para lo que se realizó un estudio bibliométrico en el que se revisaron más de 150 artículos, los cuales fueron leídos completamente e identificados los mas relevantes, posteriormente se identificaron los aspectos y datos más significativos y se complementó con la experiencia propia de los autores..

\section{Productos de hormigón y cemento}

Teniendo en cuenta que entre el 8 y el 10 $\%$ de las emisiones de $\mathrm{CO}_{2}$ provienen de la fabricación del cemento [16], algunos autores han realizado estudios para reducir el consumo de energía durante su proceso de fabricación, incluyendo técnicas como la sustitución de un porcentaje de cemento por ceniza volante, el uso de otras puzolanas naturales, el desarrollo de hormigón con residuos de materiales y el nanoconcreto [16], [17]. Sin embargo, el sector de la nanotecnología de materiales de construcción eco-eficientes no ha sido muy investigado; la nanotecnología hasta ahora se ha centrado principalmente en las zonas de alta rentabilidad [11].

Comparando las propiedades de ingeniería del concreto con adiciones de residuos de hormigón generados en la construcción y demolición, residuos de probetas de laboratorio de hormigón de una compañía de premezclado comercial, y un agregado regular del mercado, se obtuvo que los áridos compuestos con residuos son menos densos, menos porosos, con mayor absorción de agua y menor resistencia a la compresión, tensión y flexión [2], siendo materiales útiles para aplicaciones que no requieran estar sometidos a grandes fuerzas.

Diversos autores han logrado producir concreto reciclado con adiciones de residuos de neumáticos y botellas de plástico, en reemplazo al agregado grueso y arena en las 
mezclas comunes de concreto, encontrándose que el material posee un buen valor de resistencia a la tracción [18], permitiendo no solo mejoras en el rendimiento del pavimento de carreteras de tráfico liviano y aceras [19], sino que con ello se minimiza la contaminación producida por las grandes cantidades de neumáticos desechados y el uso de agregado grueso convencional no renovable [20]. En otras aplicaciones civiles, como los bloques de concreto, se han realizado investigaciones para la adición de polímeros como el etileno acetato de vinilo (EVA), residuos de producción de plantillas y suelas, como agregado ligero en la fabricación de bloques de hormigón no estructurales, cuyos resultados indican que existen buenas expectativas del componente, con una nueva propuesta de geometría, pudiendo contribuir a la eficiencia energética de edificios mediante aislamiento térmico de las paredes [21], reduciendo el nivel de ruido de impacto en hasta $15 \mathrm{~dB}$ en los techos [22] y disminuyendo la temperatura de mezcla del asfalto [23].

El bagazo de la molienda de piña de agave, aserrín y poliestireno expandido de empaques y embalajes, se han usado como elementos de refuerzo y estabilización de adobes [24], logrando un incremento en sus propiedades mecánicas, químicas, térmicas, densidad, entre otras, haciendo a estos materiales fuertes candidatos para la arquitectura de bajo costo, ya que el $50 \%$ de las casas del mundo están compuestas de este material [25]. Las fibras naturales en general, han sido usadas para mejorar las propiedades de varios materiales de construcción, por su resistencia a la tracción y bajo módulo de elasticidad, aun cuando dependiendo de su naturaleza, puede variar significativamente en algunas propiedades [11]; entre tanto, el poliestireno expandido se caracteriza por su gran ligereza ( $98 \%$ aire y $2 \%$ poliestireno), alta capacidad de absorber energía causada por golpes y vibraciones, excelente aislante térmico, y resistencia a los rayos UV [26].
A pesar de que estos y otros estudios realizados sobre la producción de cemento modificado con polímeros, rescatan propiedades de estos materiales, como su procesado, resistencia, durabilidad, y las propiedades mecánicas estáticas, en la actualidad se le ha prestado poca atención, aun cuando las condiciones de carga dinámica se encuentran comúnmente en los sistemas de infraestructura civil [27], debido probablemente a que la evaluación del potencial de sostenibilidad de estos materiales de construcción, no sólo implica su impacto ambiental y el rendimiento técnico, sino la garantía de una vida útil que aún no ha sido resuelta [28].

No obstante, las técnicas de inclusión de residuos naturales en las pastas de cemento, ha sido una línea de investigación muy atractiva para ciertos autores, afirmando que las fibras naturales son tan fuertes como las fibras sintéticas, son rentables y responden a la necesidad del medio ambiente [12]. Algunas de las fibras más analizadas para estos materiales de construcción son cenizas de bagazo de caña de azúcar, las cenizas volantes, cenizas de cenicero de centrales termoeléctricas, cenizas de cascarilla de arroz, entre otras [29].

En las mezclas de cemento con cenizas volantes y cenizas de cenicero, se logra identificar una mayor actividad puzolánica de las cenizas volantes, aunque ambas proporcionan resistencias a la compresión y a la flexión dentro de la normativa vigente, pudiendo considerarse desde un punto de vista mecánico como constituyente principal de los cementos Portland comunes [30]. Por otra parte, las cenizas de caña de azúcar pueden ser consideradas como material alternativo en la producción de morteros y probablemente en concretos, puesto que mejoran diversas propiedades como la resistencia a la compresión con adiciones inferiores al $10 \%$, resistencia a tracción por compresión diametral con adiciones del $3 \%$, y reducción de
Enero - Junio 2017 ISSN 0122-820X E-ISSN 2422-5053 PP: 6-16 
la absorción capilar, previniendo el ingreso de agentes agresivos al mortero y, en particular, reduce el impacto ambiental causado por su inadecuada eliminación [31]; Vidal et al. [32] concluyeron que las propiedades de la ceniza de bagazo de caña varían en torno a las condiciones del proceso de combustión y acorde a su calidad se determina si puede ser utilizada como adición al cemento Portland.

Dentro de los estudios para el uso de la cascarilla de arroz, se encontró que es posible usarla con o sin pretratamientos como aditivo en la fabricación de morteros ligeros de elevada porosidad, lo que la convierte en candidata para elaborar materiales de construcción para aislamiento térmico y acústico, pero debido a su baja resistencia mecánica en comparación a los morteros y hormigones tradicionales, no son aptos para fabricar elementos portantes [33], al igual que los morteros con agregado de ceniza de cascarilla de oliva, los cuales, a mayor adición, presentan los siguientes comportamientos en comparación a la pasta de cemento ordinario: menor consistencia normal, aumento en los tiempos de fraguado inicial, disminución de la solidez de la expansión, la cual aumenta con el aumento del porcentaje de residuos de oliva, disminución de la resistencia a la compresión y flexión, y mayor resistencia al deterioro por reacción álcali-sílice [34].

\section{Productos cerámicos}

Los residuos industriales como lodos de aguas residuales urbanas y de la industria cervecera, bagazo de caña, residuos del procesamiento de café, entre otros, han sido utilizados para mezclarse con arcilla para producir ladrillos, lozas, y demás productos cerámicos, analizando su influencia en el comportamiento de la contracción lineal, densidad aparente, absorción de agua, y propiedades mecánicas $\mathrm{y}$ térmicas [35].

Se ha evidenciado en estudios anteriores que la adición de estos materiales en las pastas cerámicas permite fabricar materiales aligerados, debido a la disminución de la densidad provocada por el aumento de los poros abiertos que deja la combustión de la materia orgánica, poniendo en juego la resistencia a la compresión, y generando un ligero aumento de las propiedades de aislamiento térmico, como lo es el caso de las adiciones de lodos de aguas residuales urbanas, lodos de fabricación de cerveza, y el bagazo de caña; mientras que los poros generados por la combustión de los residuos del procesamiento de café, y del alpechín, no sólo mejora las propiedades de aislamiento térmico, sino que mantiene la resistencia a la compresión de los ladrillos [36]. Schettino y Holanda [37] caracterizaron las cenizas del bagazo de caña que fueron utilizadas para la producción de baldosas cerámicas, cuyas propiedades finales resultaron muy similares a las muestras patrón sin adición.

De igual manera la porosidad abierta se manifiesta en mezclas cerámicas con adiciones de cenizas de incinerador de biomasa [38], con el que la absorción de agua aumenta, mientras la densidad aparente y la resistencia a la compresión disminuye a mayores adiciones de este residuo, mientras que las mezclas con adición de cenizas de centrales termoeléctricas en reemplazo del feldespato [39], generan un comportamiento contrario, menor absorción de agua, mayor densidad y resistencia a la compresión.

Otros de los residuos generados a diario en grandes volúmenes, con los que se obtienen estos mismos beneficios, son los lodos de las plantas de tratamiento de aguas, que al ser utilizados como sustitutos de la arcilla en proporciones inferiores al 5\% en peso no provocan deterioro en las propiedades mecánicas de los ladrillos [40]. También se ha estudiado la posibilidad de utilizar en la cerámica los lodos procedentes de la depuración de las aguas residuales y los residuos de la limpieza de la pulpa en la 
industria del papel [41], tierra impregnada con filtración de biodiesel y su subproducto, glicerina [42], demostrándose que a mayor adición de estos residuos aumenta la expansión lineal y la absorción de agua, acompañado por la reducción de la resistencia a la compresión dentro de los limites establecidos por las normas para este tipo de materiales, y disminución de la conductividad térmica, en un $20 \%$ para las mezclas con tierra impregnada de filtración biodiesel, y hasta un $40 \%$ con adición de glicerina.

Otro tipo de lodo estudiado para modificar las propiedades mecánicas de los cerámicos de pared es el lodo de aceite de petróleo mezclado con polvo fino de vidrio, en proporción 5:1, con el que se logró mejorar las propiedades de moldeo, reducir entre 100 a $140^{\circ} \mathrm{C}$ la temperatura de cocción (de $1050-1100^{\circ} \mathrm{C}$ a $950-970^{\circ} \mathrm{C}$ ), e incrementar la resistencia al frío, con adiciones de 30$35 \%$, sin procesos tecnológicos especiales de preparación. Otras propiedades como densidad e índice de resistencia no sufrieron variaciones representativas [43].

$\mathrm{La}$ industria del aluminio genera anualmente grandes cantidades de un subproducto conocido como "lodo rojo", el cual ha sido estudiado para su uso como materia prima secundaria en la fabricación de ladrillos de cerámica [44], que a diferencia de los materiales anteriormente mencionados, puede proporcionar altas resistencias a la compresión, ya que la fase líquida llena los poros. Con una adición del $50 \%$ de "lodo rojo" se puede aumentar la resistencia a la compresión, disminuir la absorción de agua y la conductividad térmica, obteniéndose valores de contracción lineal de 0,46\%, absorción de agua de $21 \%$, pérdida por fuego de $12,6 \%$, y resistencia a la compresión de $52.54 \mathrm{MPa}$, además de reducir la conductividad térmica a medida que se aumenta la adición de este material. Otro tipo de residuos del procesamiento de metales como la escoria de acero, polvos blancos, lodos de hornos y refractarios de aluminosilicatos fueron estudiados para determinar su influencia en los productos cerámicos obtenidos por extrusión [45], obteniéndose como resultado que como estos materiales poseen un índice de plasticidad muy bajo, se ve afectado negativamente el moldeado de los productos formados por extrusión.

En la industria cervecera también se generan residuos como tierra diatomácea y lodo de cal que pueden ser aprovechados en la fabricación de bloques de mampostería de perforación horizontal, no estructural, que se utilizan para muros divisorios o de cierre que únicamente atienden las cargas debido a su propio peso, con adiciones hasta el $10 \%$ en peso, obteniéndose productos de menor masa, sin presencia de alabeos ni laminaciones, con mayor resistencia a la compresión [46].

Hasta el momento se ha visto como diferentes residuos han sido estudiados para reemplazar cantidades de arcilla en la producción de artículos cerámicos. Sin embargo, también existen estudios para remplazar el agua dulce de la mezcla de ladrillos mediante extrusión por aguas residuales de la extracción de aceite de oliva [47], con los que se logró mejorar ligeramente las propiedades físicas, mecánicas y térmicas de los ladrillos; comportamiento atribuido a la generación de poros cerrados. Asimismo, se ha estudiado el reemplazo de ciertas proporciones de feldespato por cenizas de tamo de arroz en las mezclas de pastas de loza [48], obteniéndose menor porosidad aparente, porosidad total y absorción de agua, y aumento en la resistencia a la compresión, con sustituciones hasta de un $75 \%$ del feldespato.

Los pigmentos cerámicos también han sido objeto de estudio por algunos autores, por ejemplo, se ha propuesto un método para el uso de los desechos de las capas protectoras de los reactores químicos de las refinerías de petróleo, adicionando reactivos de alta pureza ( $\mathrm{MgO}, \mathrm{Cr}_{2} \mathrm{O}_{3}, \mathrm{Fe}_{2} \mathrm{O}_{3}$, y $\mathrm{HNO}_{3}$ ), con los que se
Enero - Junio 2017 ISSN 0122-820X E-ISSN 2422-5053 PP: 6-16 
Uso de nutrientes tecnológicos como materia prima en la fabricación de materiales de construcción en el paradigma de la economía circular han preparado mezclas homogéneas en forma de pastillas, que sometidos a $800^{\circ} \mathrm{C}$ durante una hora, se transforman en pigmentos cerámicos con alta densidad (1,85 a 2,60 g/ $\mathrm{cm}^{3}$ ) y una porosidad abierta entre 28,9 y $32,93 \%$ a $700^{\circ} \mathrm{C}$, esta última se calcula por medio de la relación en porcentaje entre el volumen de los poros abiertos y el volumen aparente de la pieza [49].

\section{El paradigma de la economía circular}

Se puede apreciar como se han avanzado estudios, que promueven el cambio de los procesos productivos, donde los residuos se observan ahora como recursos para la producción de nuevos productos, manteniendo e incluso mejorando algunas de sus propiedades, favoreciendo una producción mas limpia y generando un nuevo sistema económico para las empresas: "economía circular". Para adoptar este nuevo sistema, se necesita el apoyo de los gobiernos y las comunidades, siendo estos los promotores de una conciencia ambiental que incluya los objetivos encaminados a disminuir la contaminación y el aprovechamiento de residuos [50], de no ser así las reservas de recursos a nivel mundial desaparecerán; sin embargo, se ha expuesto que el crecimiento de este nuevo modelo se ve amenazado por los costos del uso de estos residuos y la proporción de su uso [51], representando retos a nivel de ingeniería, teniendo como tarea principal transformar los procesos de producción incluyendo como materias primas residuos de otros procesos, por lo que se deberá intervenir en el tratamiento de materias primas, productos intermedios y control de calidad de productos finales [52].

\section{Conclusiones}

En un esfuerzo por contribuir al desarrollo y difusión de tecnologías sostenibles y como respuesta al crecimiento del sector de la construccióny de losresiduos generados, sehan recopilado y analizado diferentes trabajos de investigación que usan residuos industriales y agroindustriales como nutrientes tecnológicos en la elaboración de materiales de concreto y cerámicos, identificando que además de mitigar el impacto ambiental generado por los residuos de los sectores productivos, ha sido posible modificar ciertas propiedades de estos materiales de construcción, como porosidad, densidad, absorción de agua, resistencia a la tensión, flexión y compresión, y conductividad térmica de ciertos productos dependiendo del residuo utilizado en su formulación.

Ya que las características de los productos obtenidos en cada una de las investigaciones analizadas difieren de los materiales tradicionales, deberán ser analizadas bajo caracterizaciones primarias y formulaciones específicas, dependiendo del tipo de uso o destino en el sector de la construcción, que además de representar un ahorro económico, le da un valor añadido a los productos con ellos fabricados debido a que con estos se contribuye a minimizar el impacto ambiental generado por los sectores productivos.

El crecimiento y mantenimiento de este nuevo sistema económico, donde su principal objetivo es el uso de los residuos industriales y/o agroindustriales para la fabricación de nuevos productos, requiere la intervención de nuevas técnicas de ingeniería, y el apoyo del sector gubernamental y social.

\section{Referencias}

[1] PROCOLOMBIA, "El mundo invierte en Colombia: inversión en materiales de construcción", s.f. [En línea]. Disponible en: http://inviertaencolombia.com.co/ sectores/manufacturas/materiales-deconstruccion.html

[2] S. Kabir, A. Al and I. M. Khan, "Recycled Construction Debris as Concrete Aggregate for Sustainable Construction Materials", Procedia 
Engineering, vol. 145, pp.1518-1525, 2016.

[3] V. Rincón, "Escombros Cero: Programa basura cero" en Primer Foro Internacional para la Gestión y Control de los Residuos de la Construcción y Demolición-RCD- (Colombia), pp. 1-25, Alcaldía Mayor de Bogotá, 2012.

[4] M. Lieder and A. Rashid, "Towards Circular Economy implementation: A comprehensive review in context of manufacturing industry", Journal of Cleaner Production, Vol. 115, no. 1, pp. 36-51, 2016.

[5] J.O. Castaño, R.M. Rodríguez, L.A. Lasso, A.G. Cabrera y M.S. Ocampo, "Gestión de residuos de construcción y demolición (RCD) en Bogotá: perspectivas y limitantes", Tecnura, vol. 17 , no. 38 , pp. 121-129, octubrediciembre 2013.

[6] M. Marrero, L. Martínez, M.P. Mercader y C. Leiva, "Minimización del impacto ambiental en la ejecución de fachadas mediante el empleo de materiales reciclados", Informes de la Construcción, vol. 65, no.529, pp.8997, enero-marzo 2013.

[7] V. Flores, J.J. Martín del Río, F.J. Blasco y F.J. Alejandre, “Análisis de impactos ambientales producidos durante la fase de ejecución en edificación: operaciones de limpieza y recuperación de aguas de lavado de hormigones en España", Informes de la Construcción, vol. 67, no.538, pp. 1-7, abril-junio 2015.

[8] J. Aldana y A. Serpel, "Temas y tendencias sobre residuos de construcción y demolición: un metaanálisis", Revista de la Construcción, vol.11, no.2, pp.416, agosto 2012.

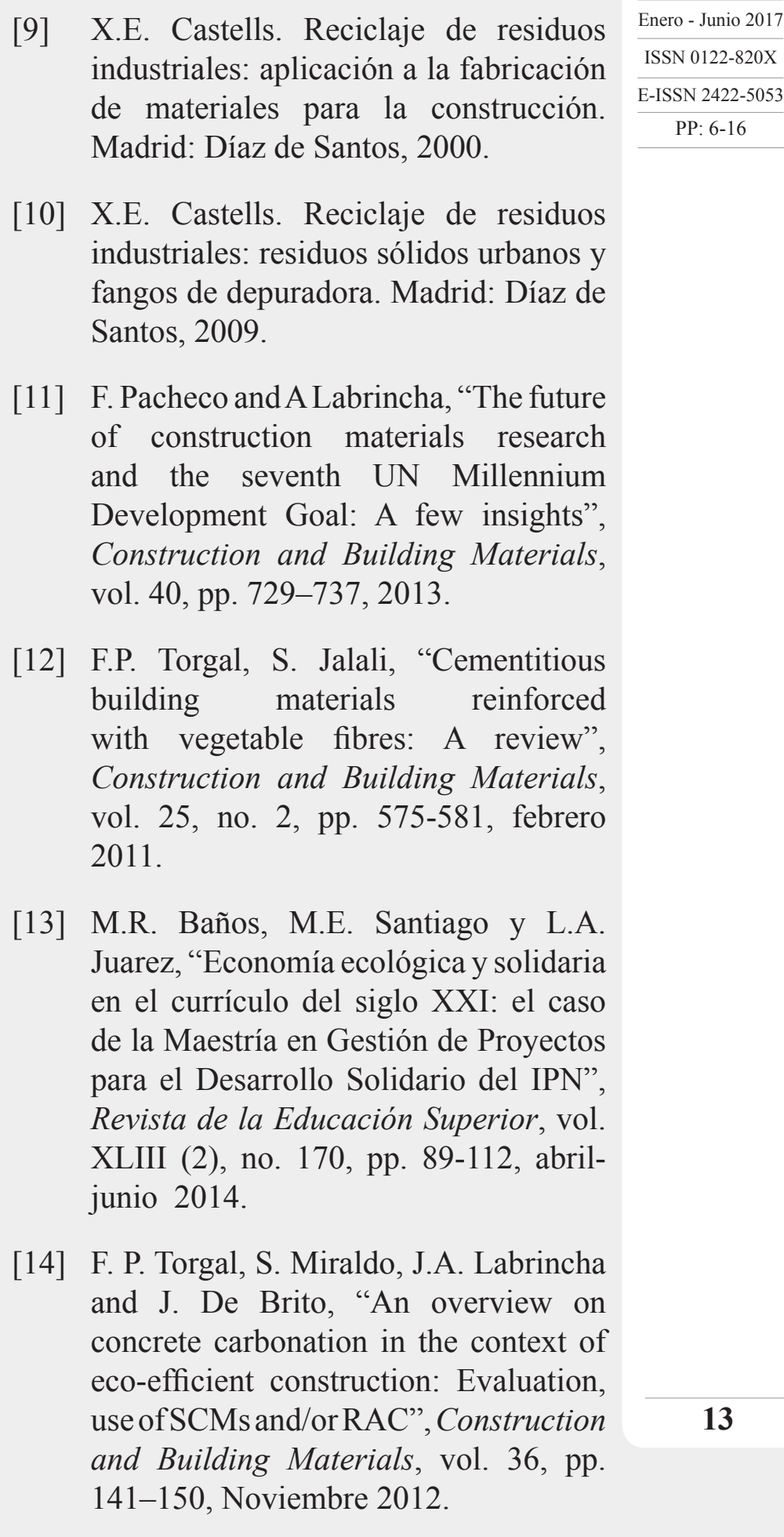

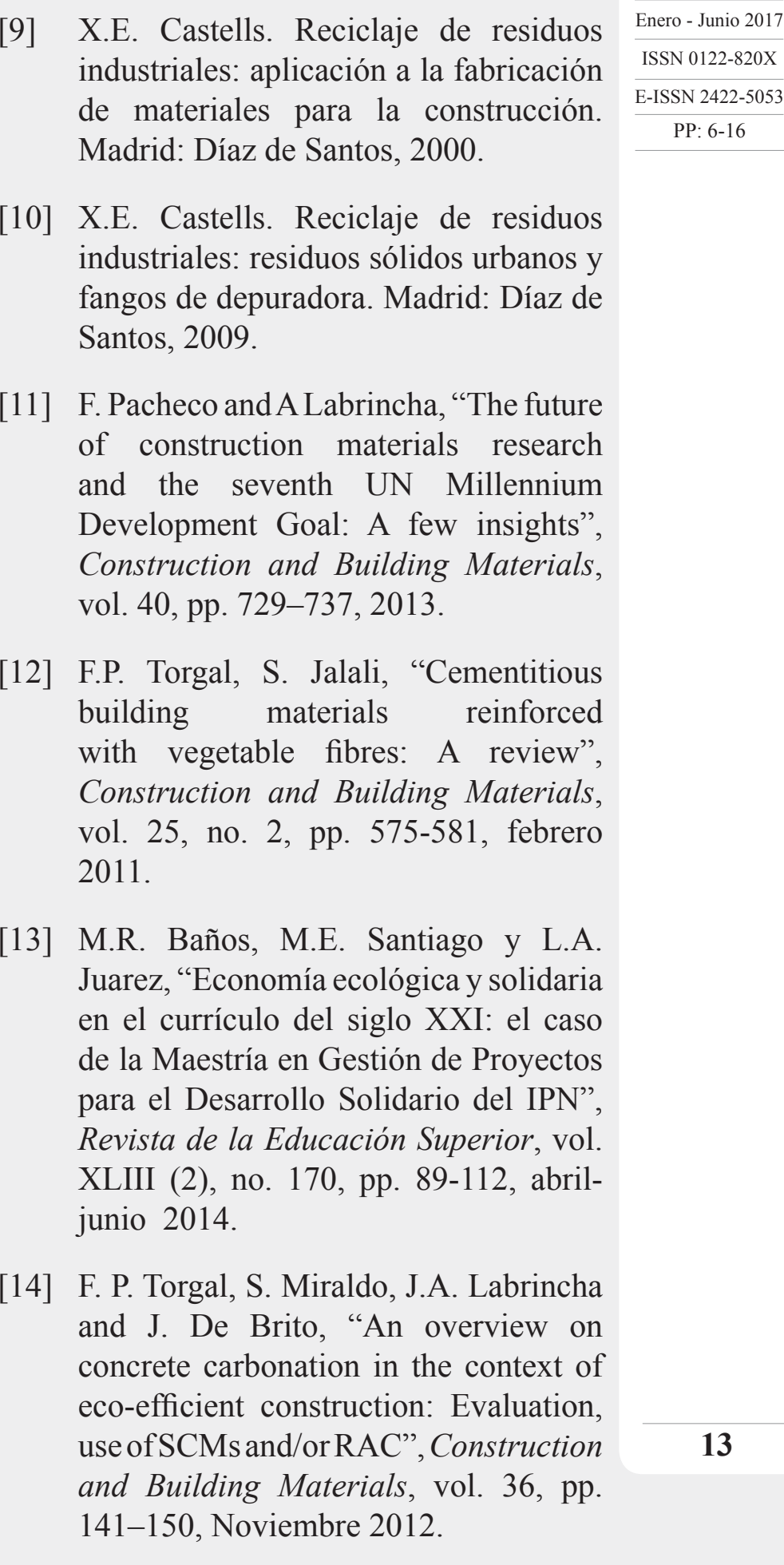

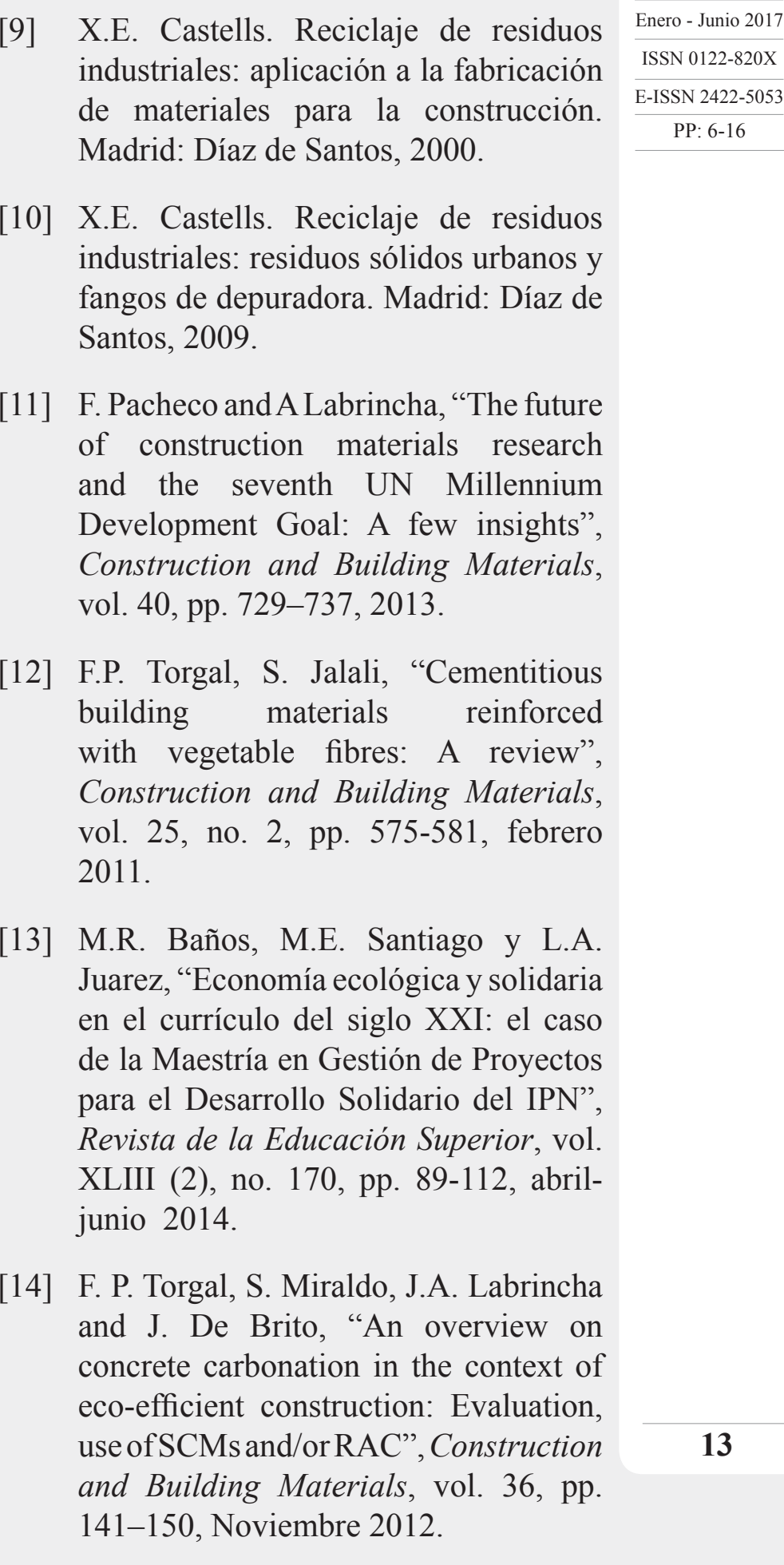

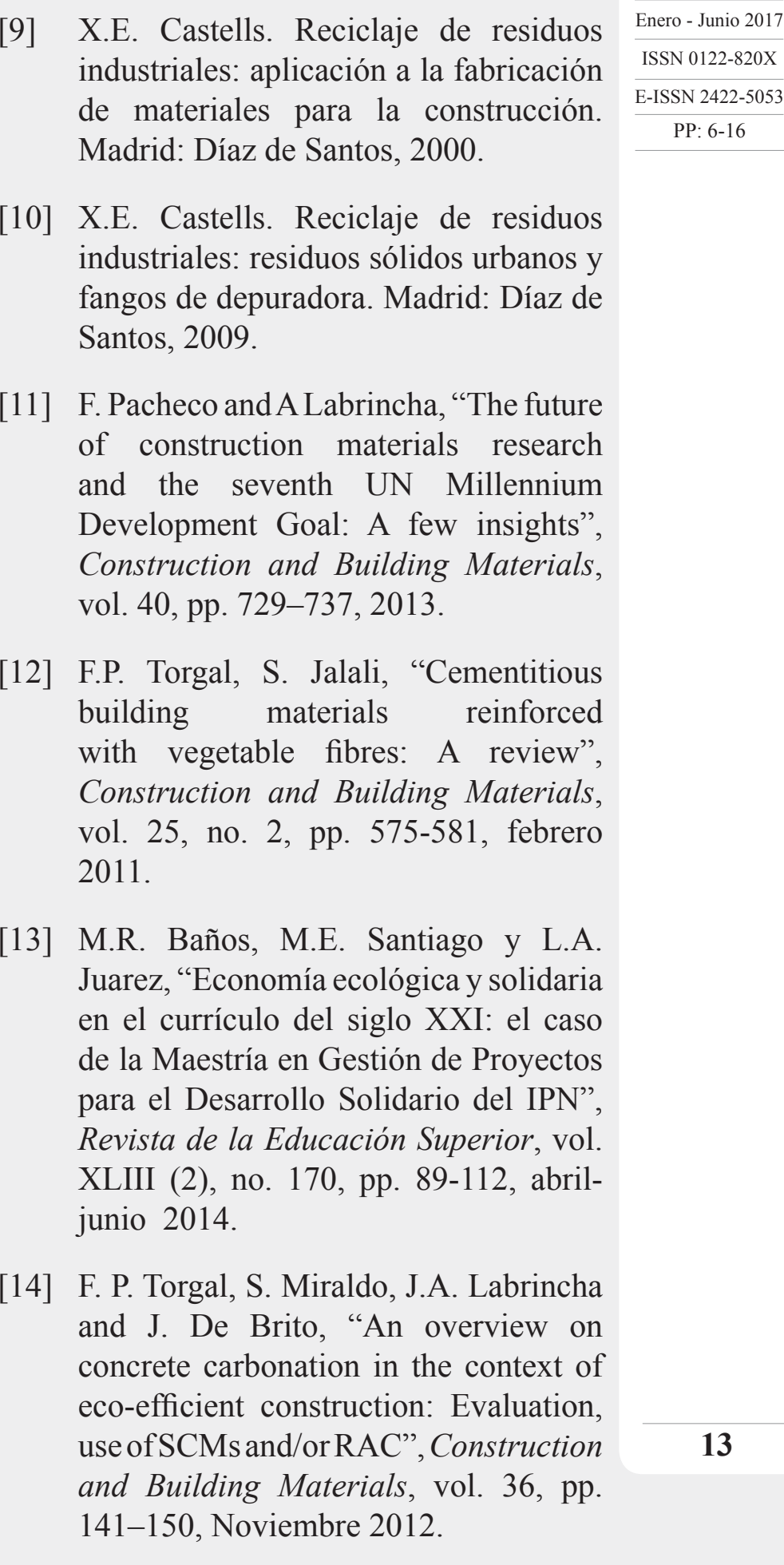

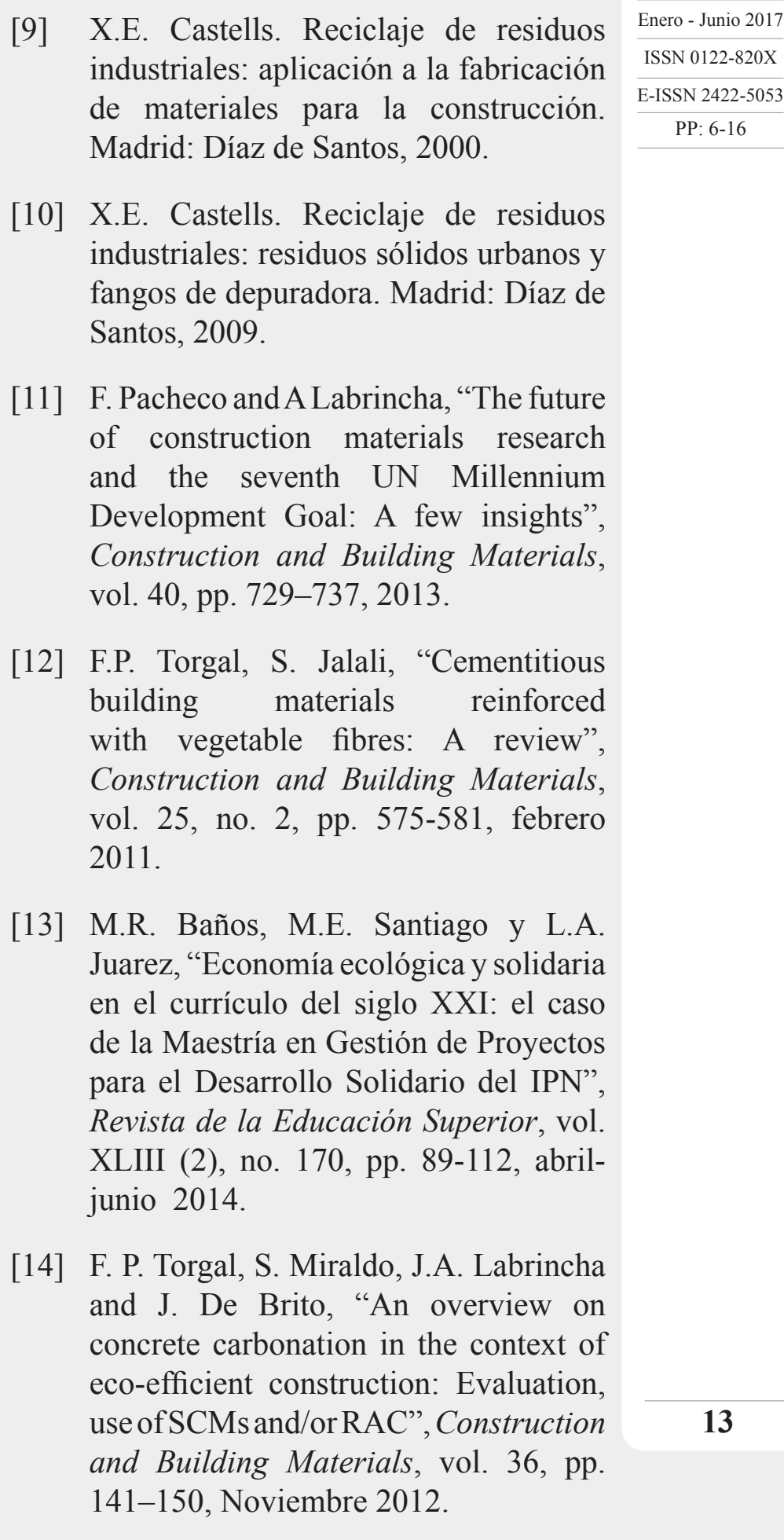

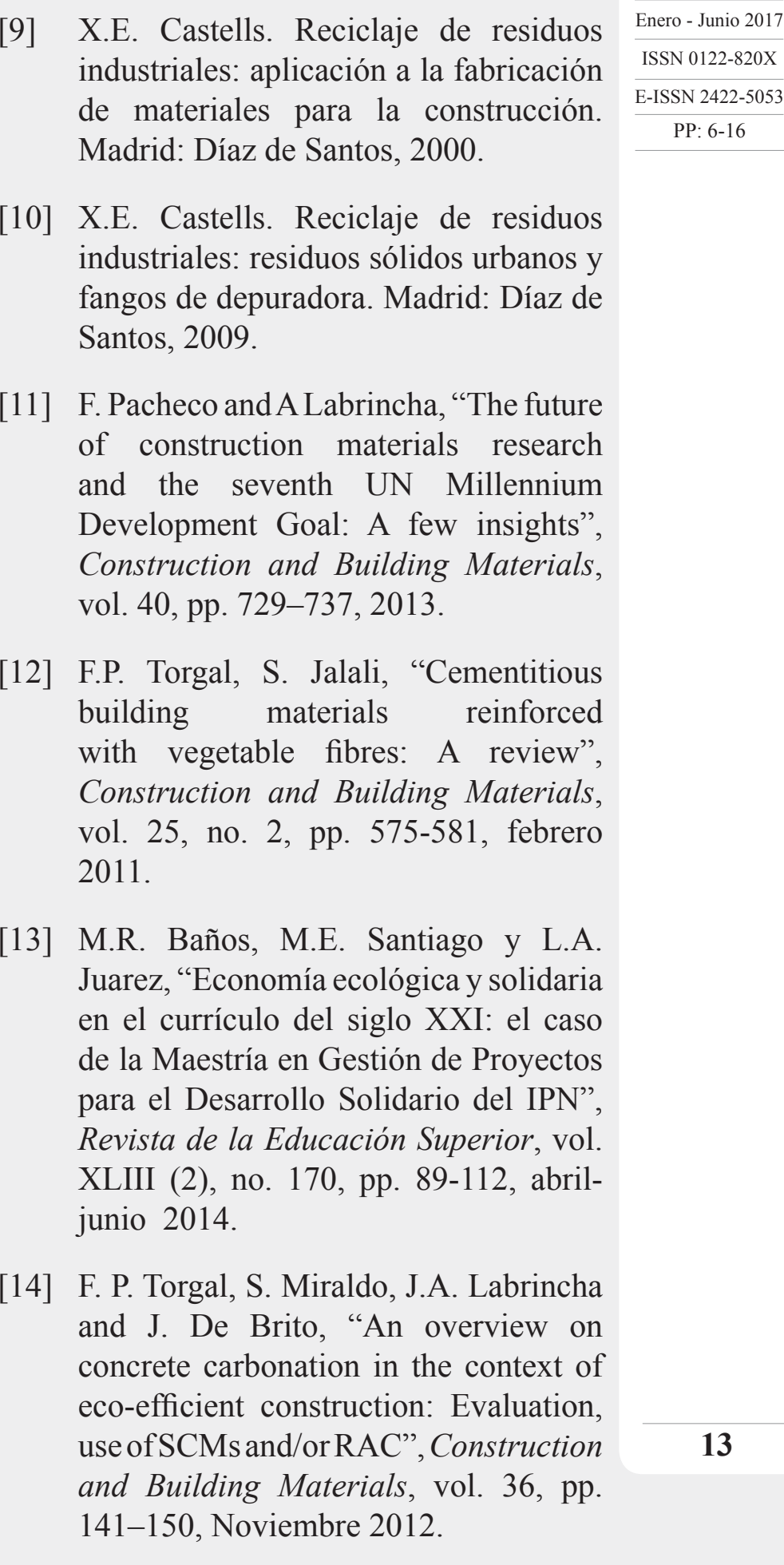

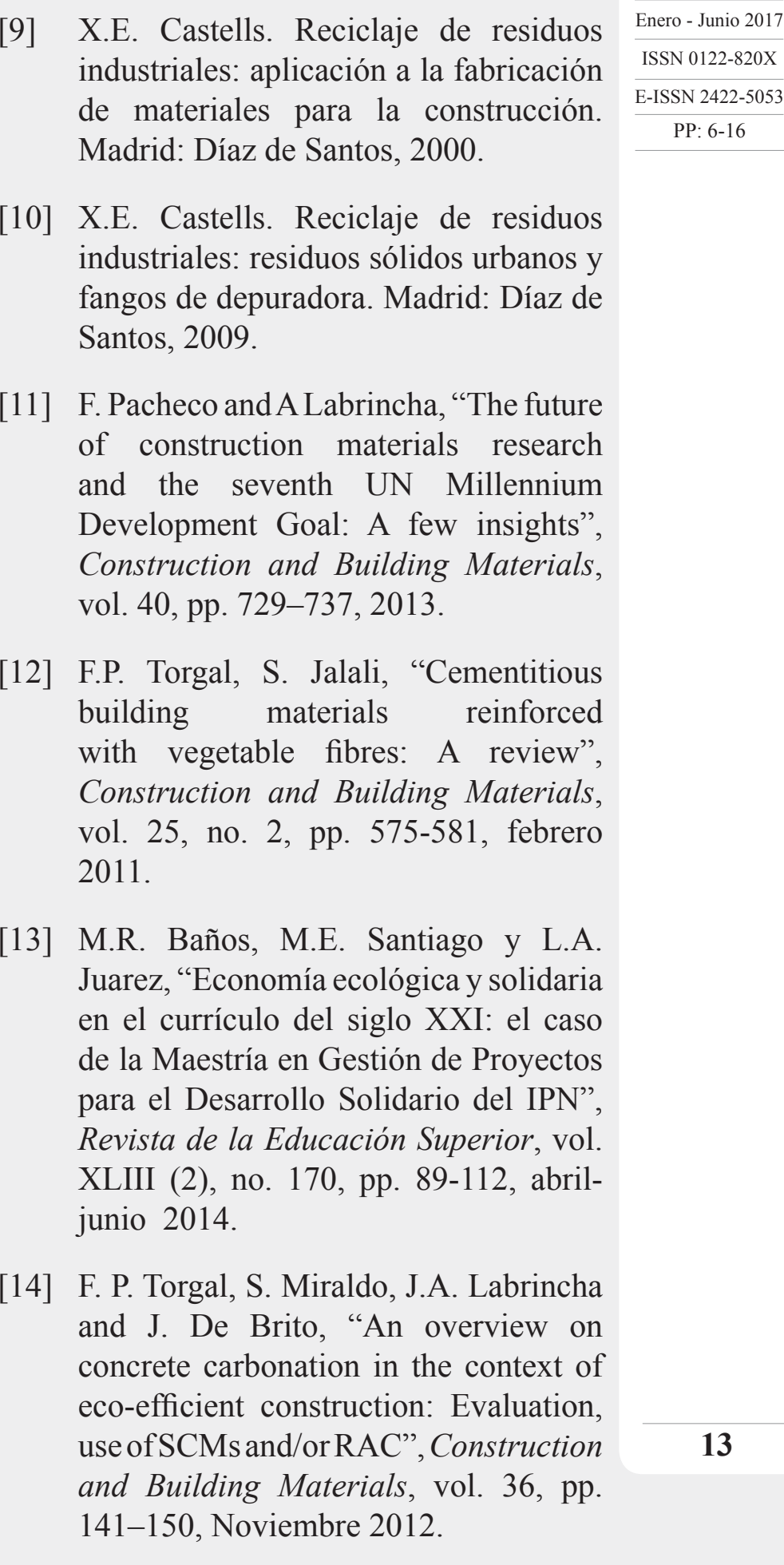

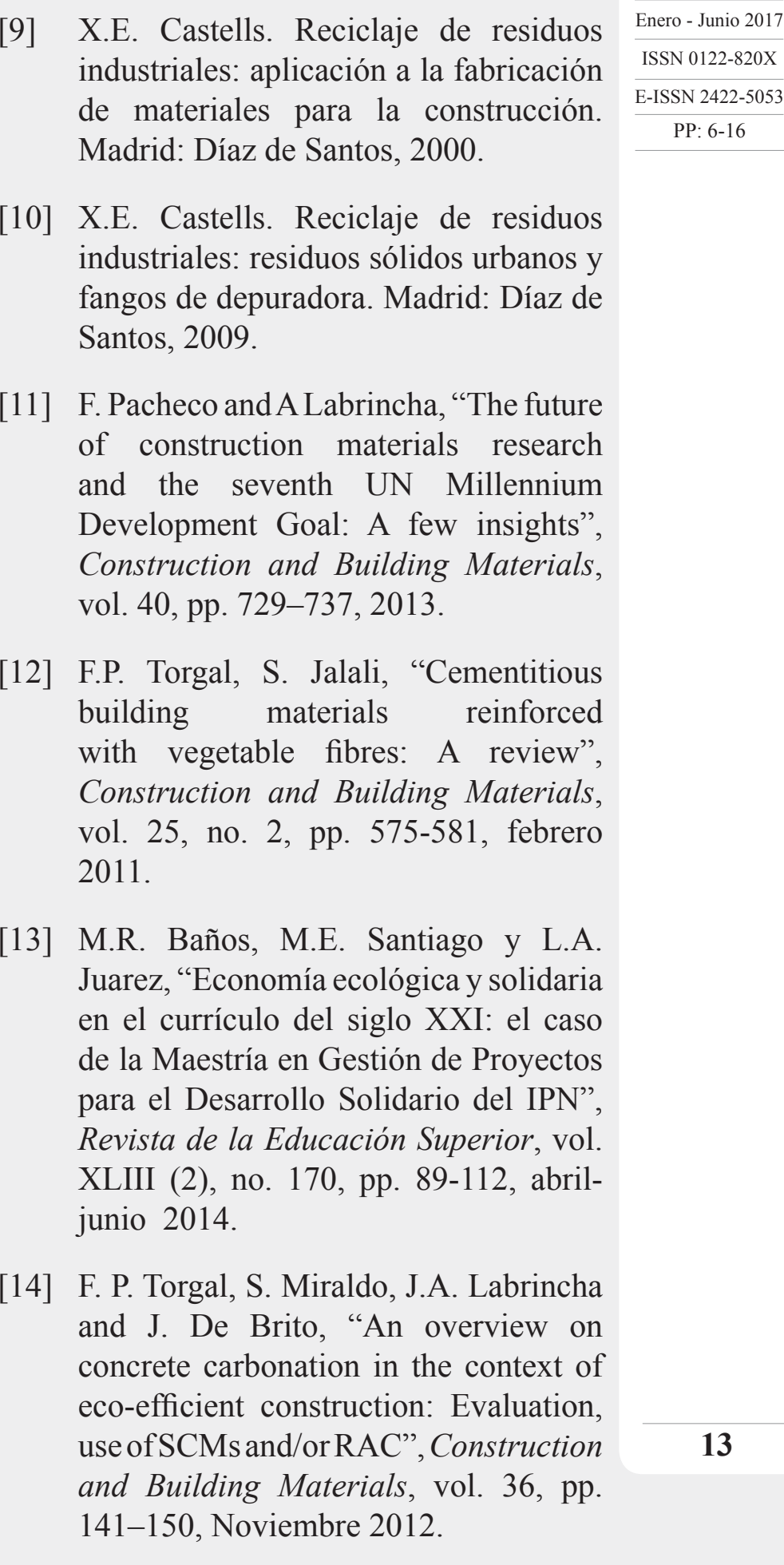

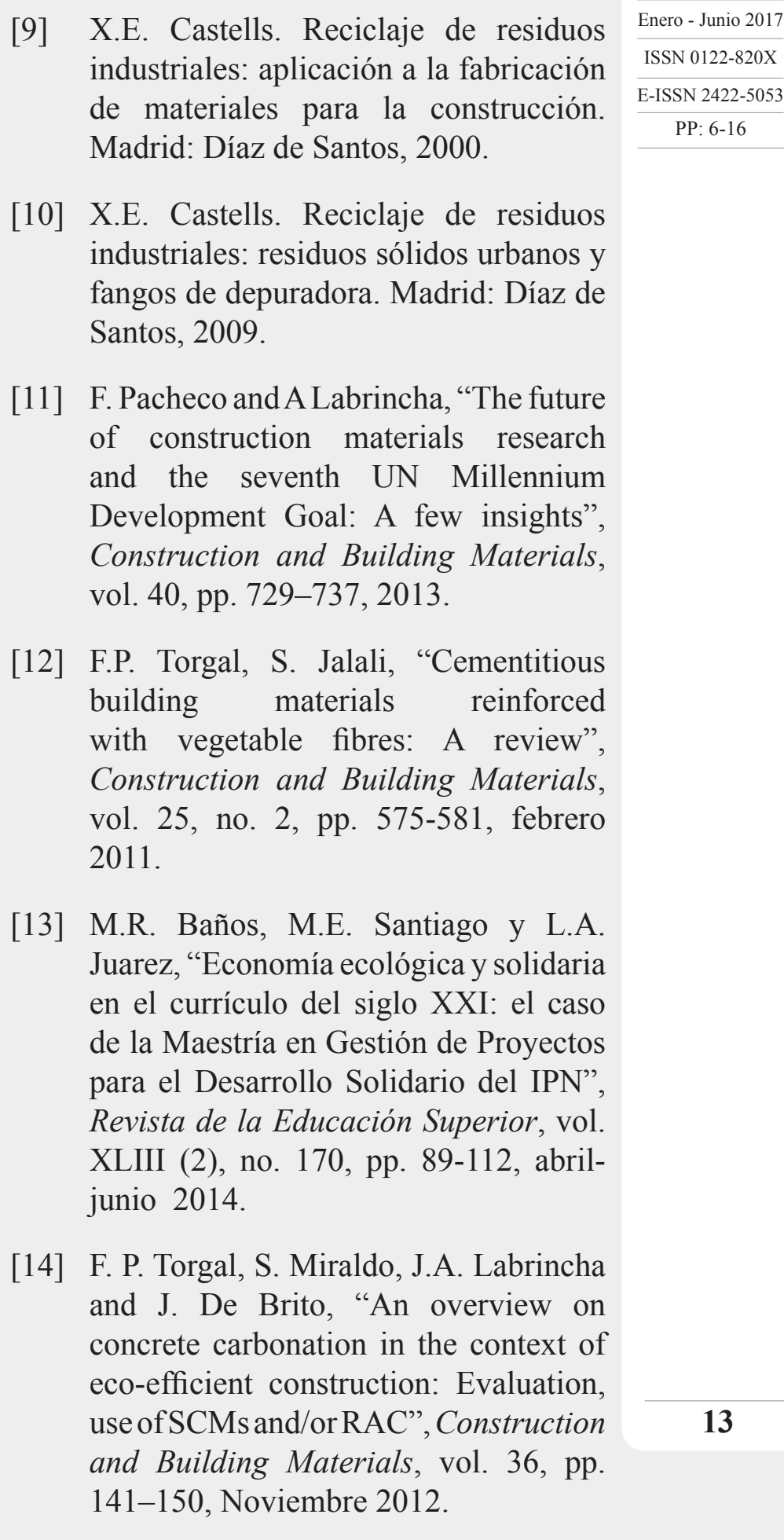

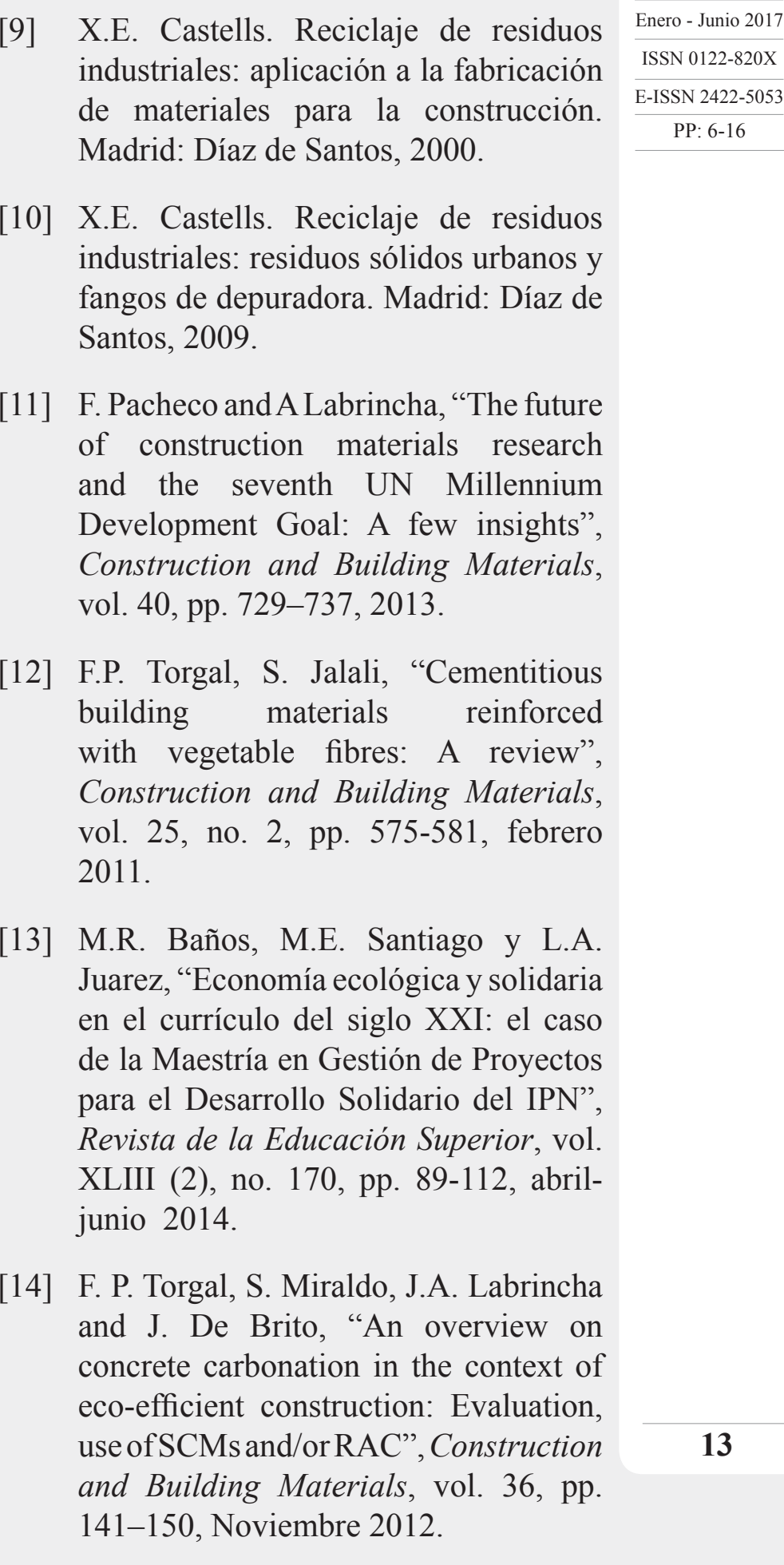

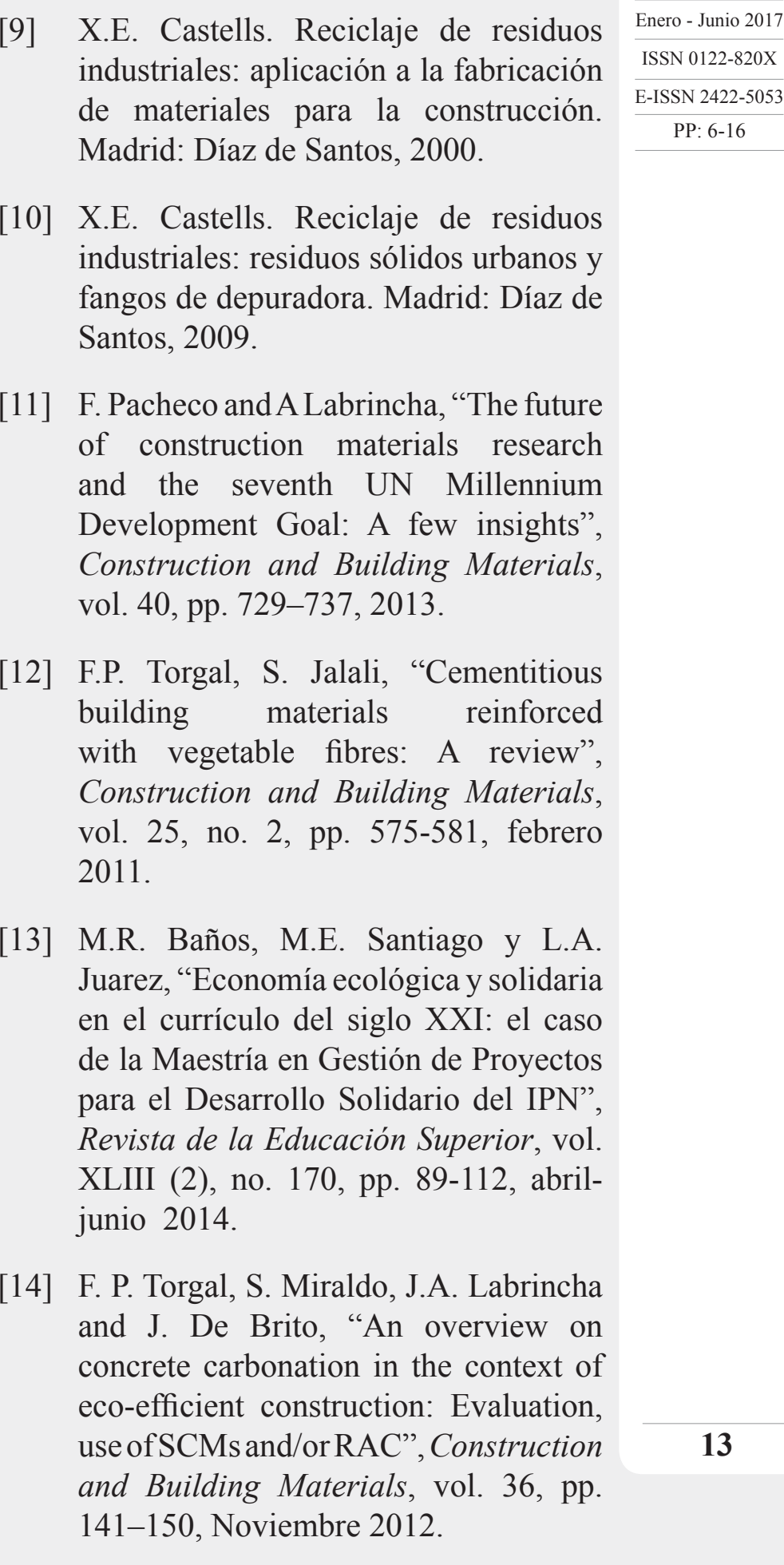

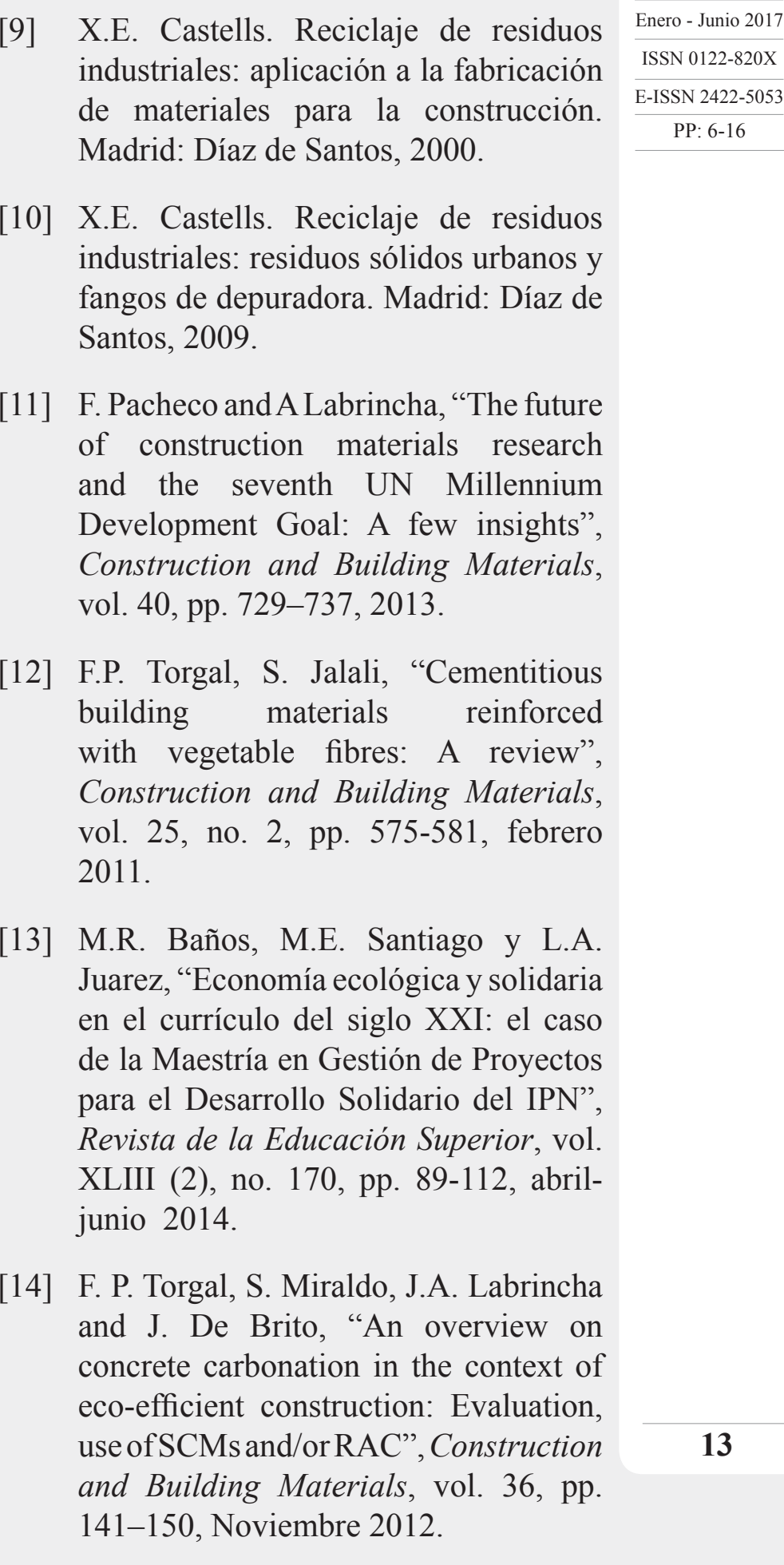

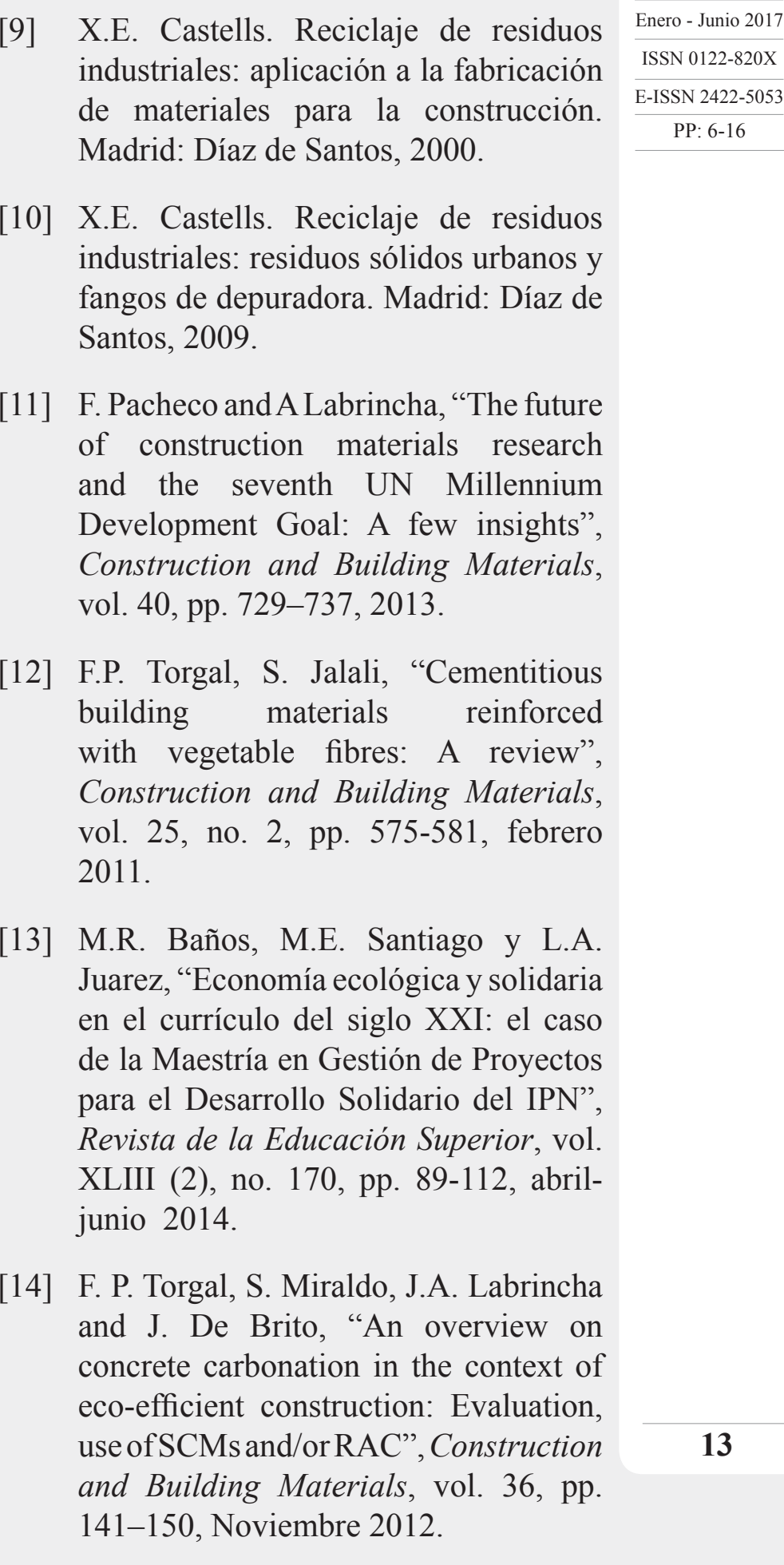

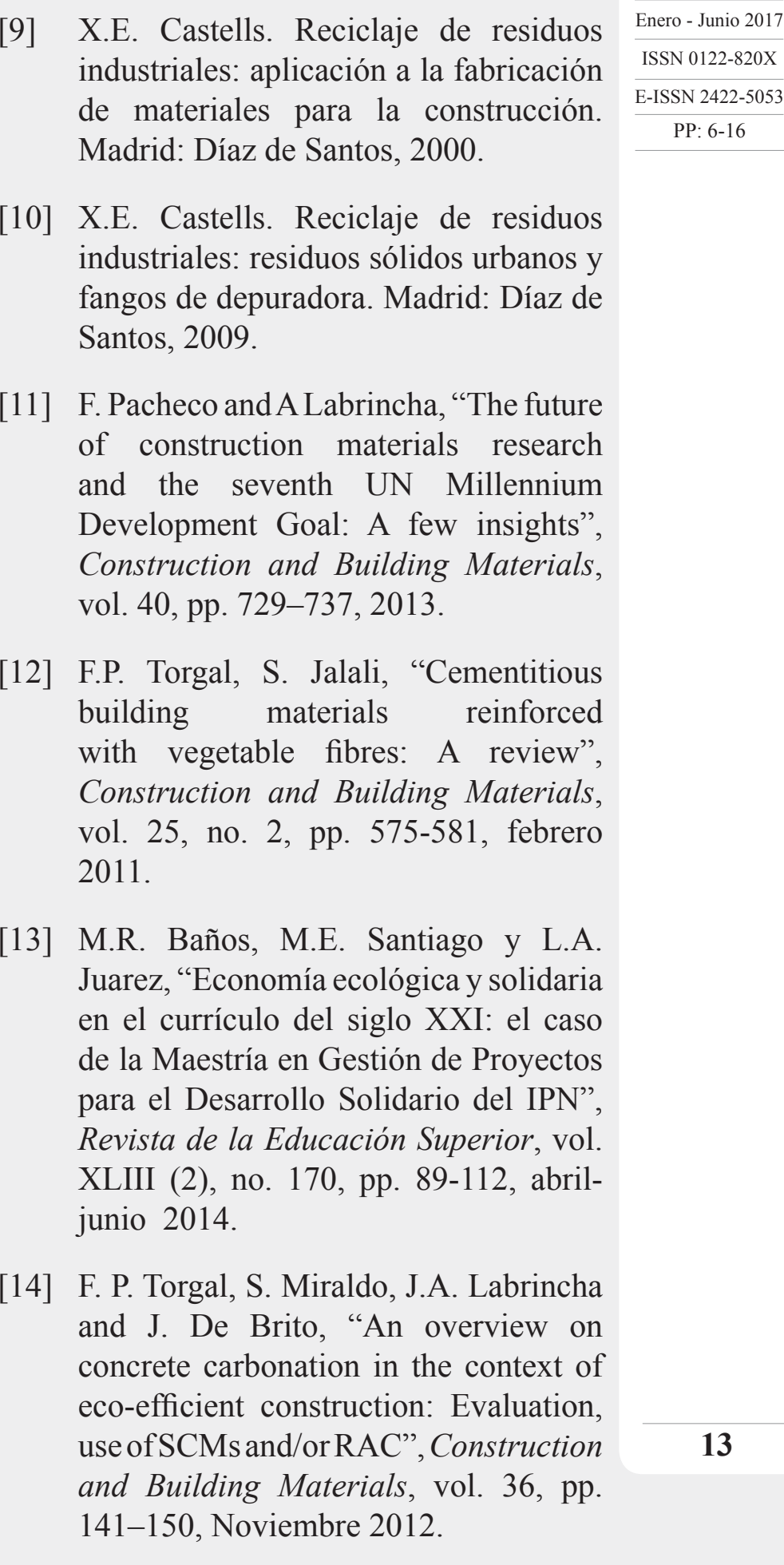

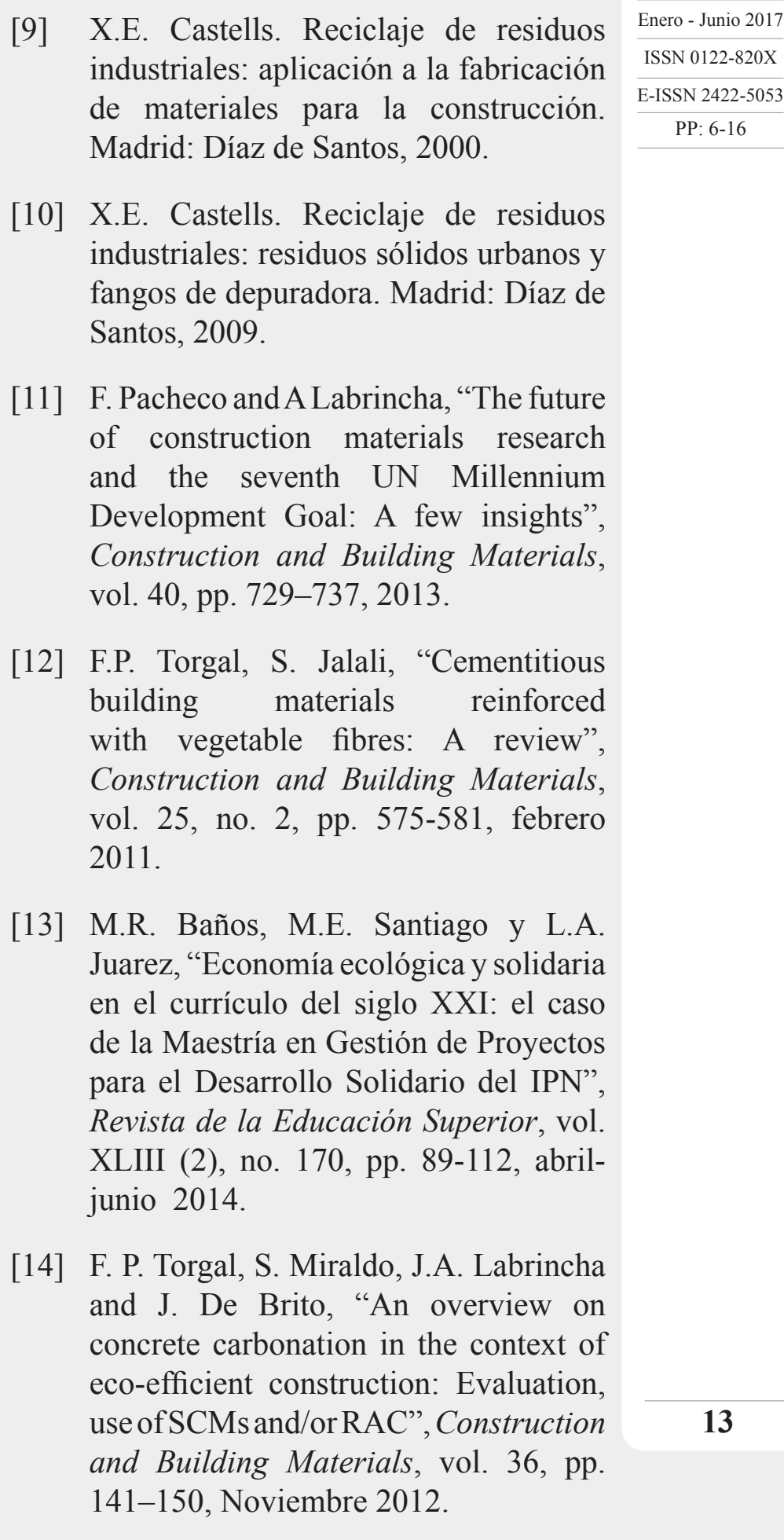

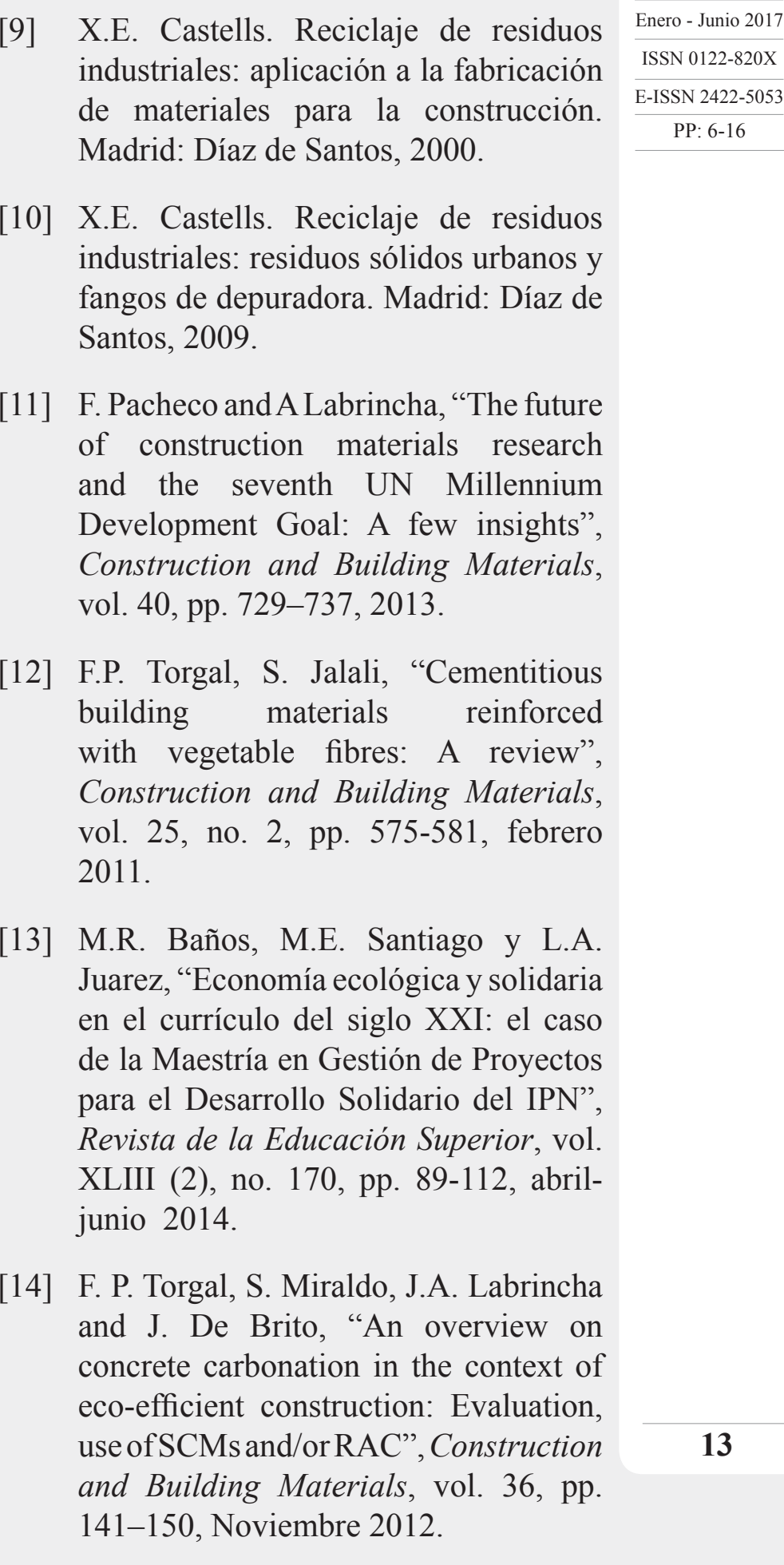

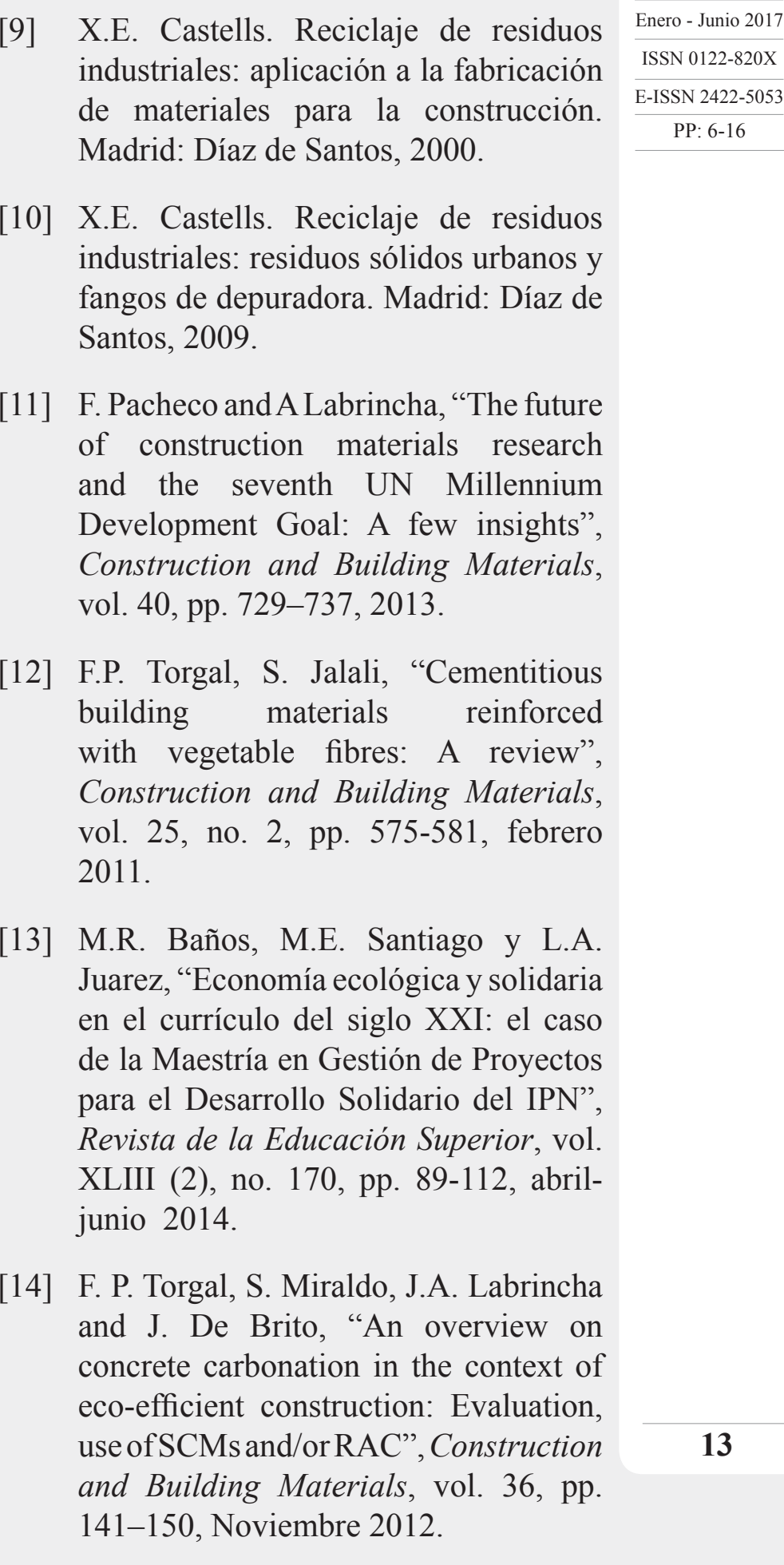

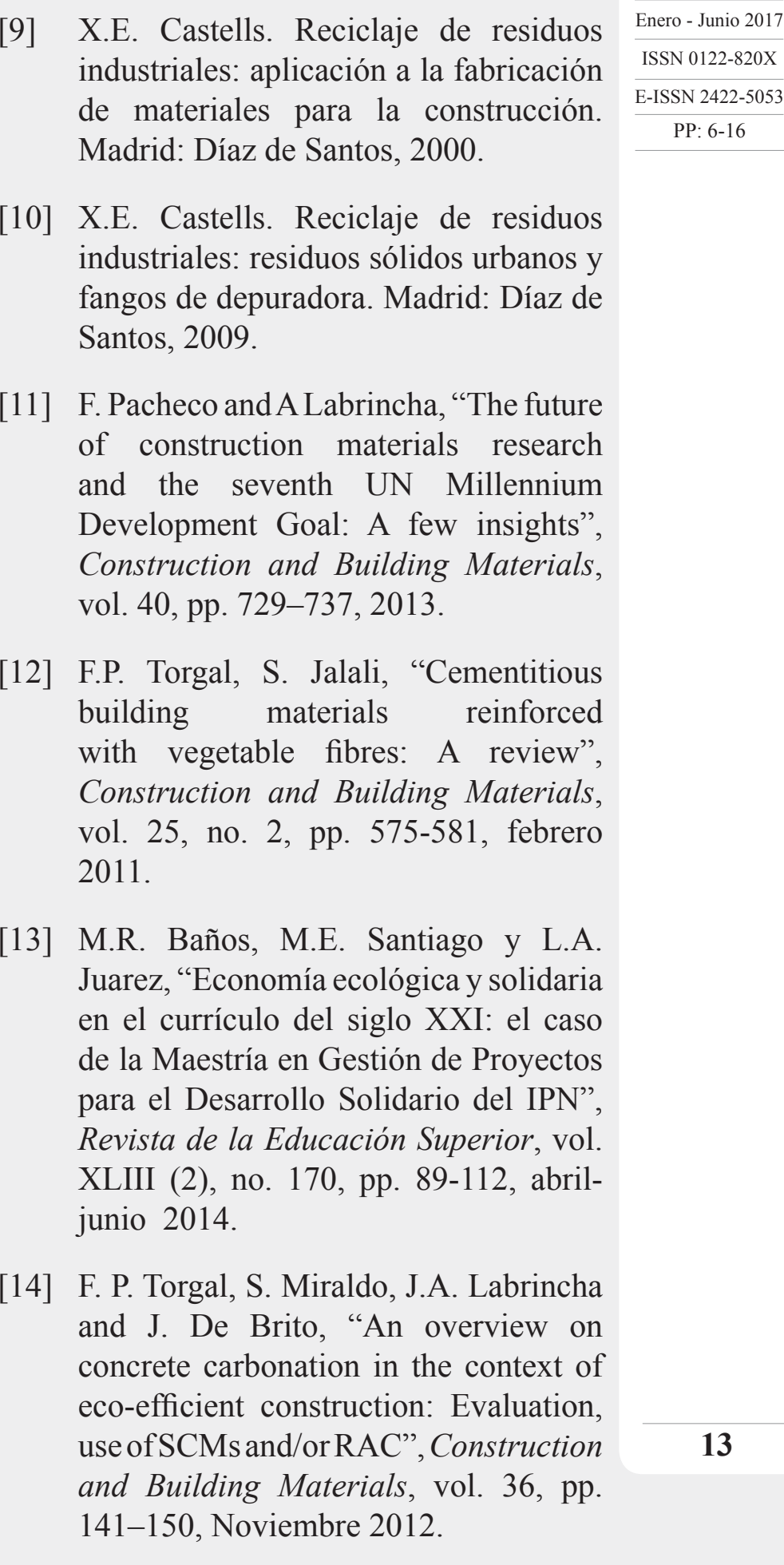

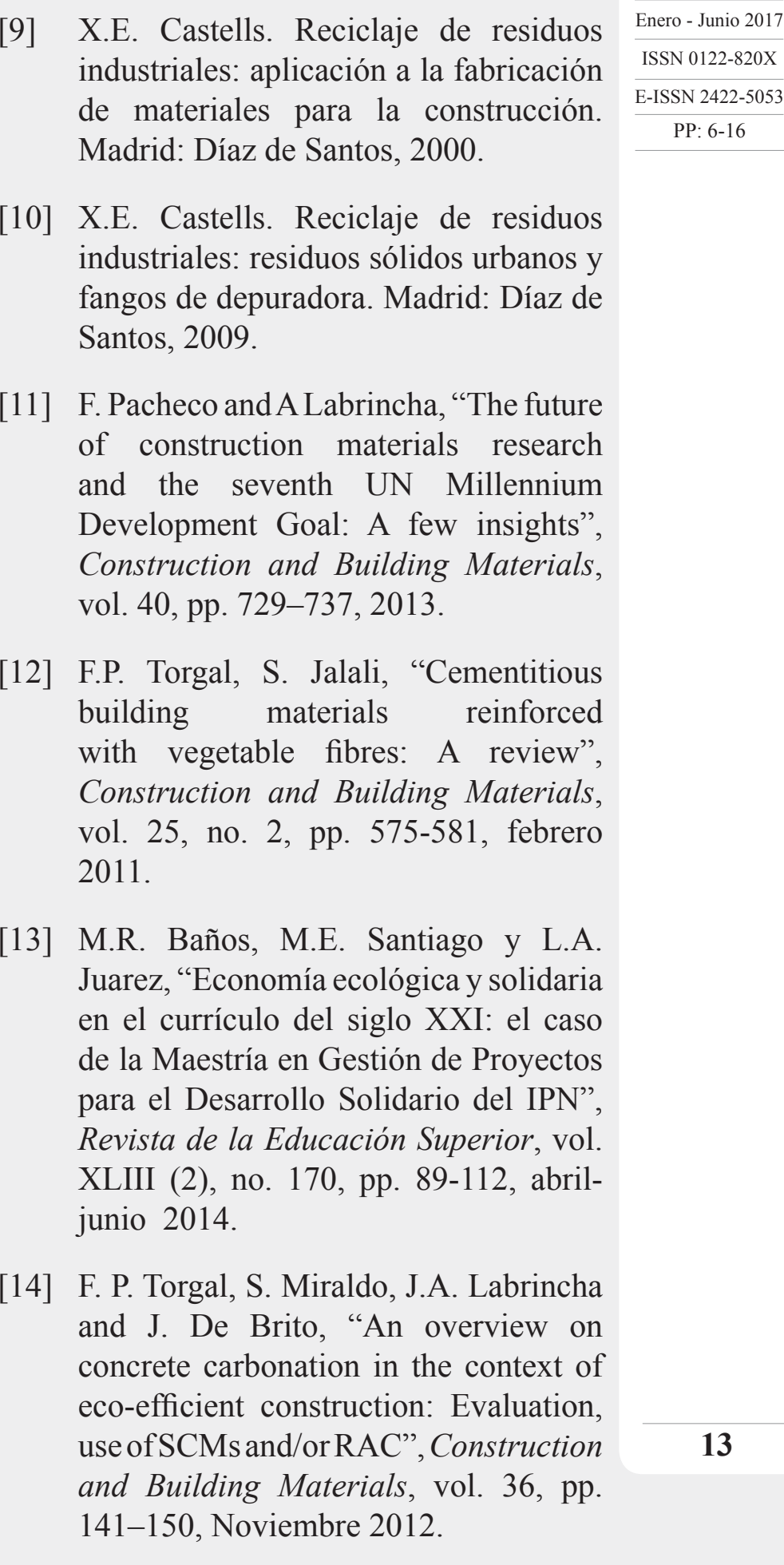

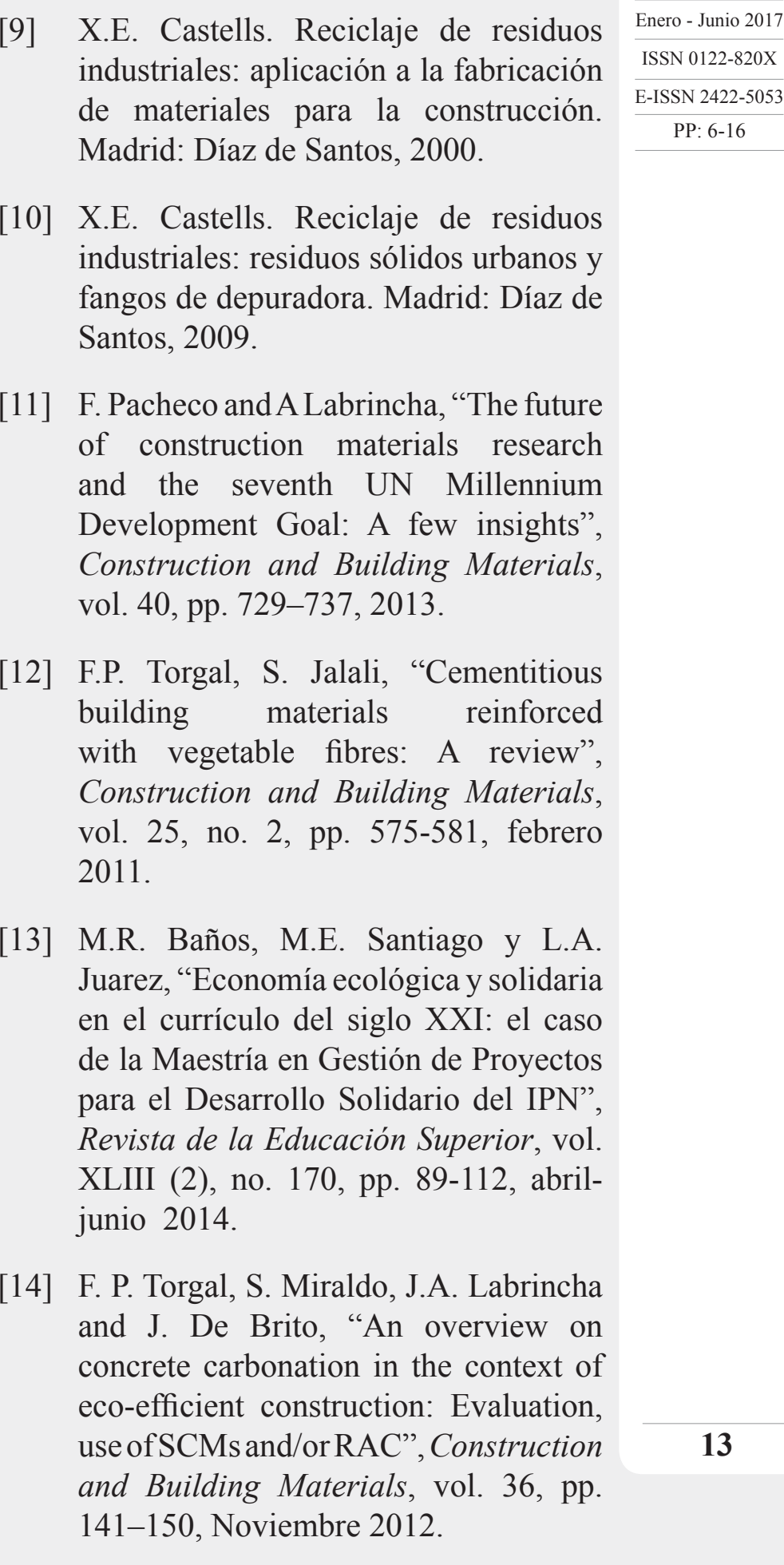

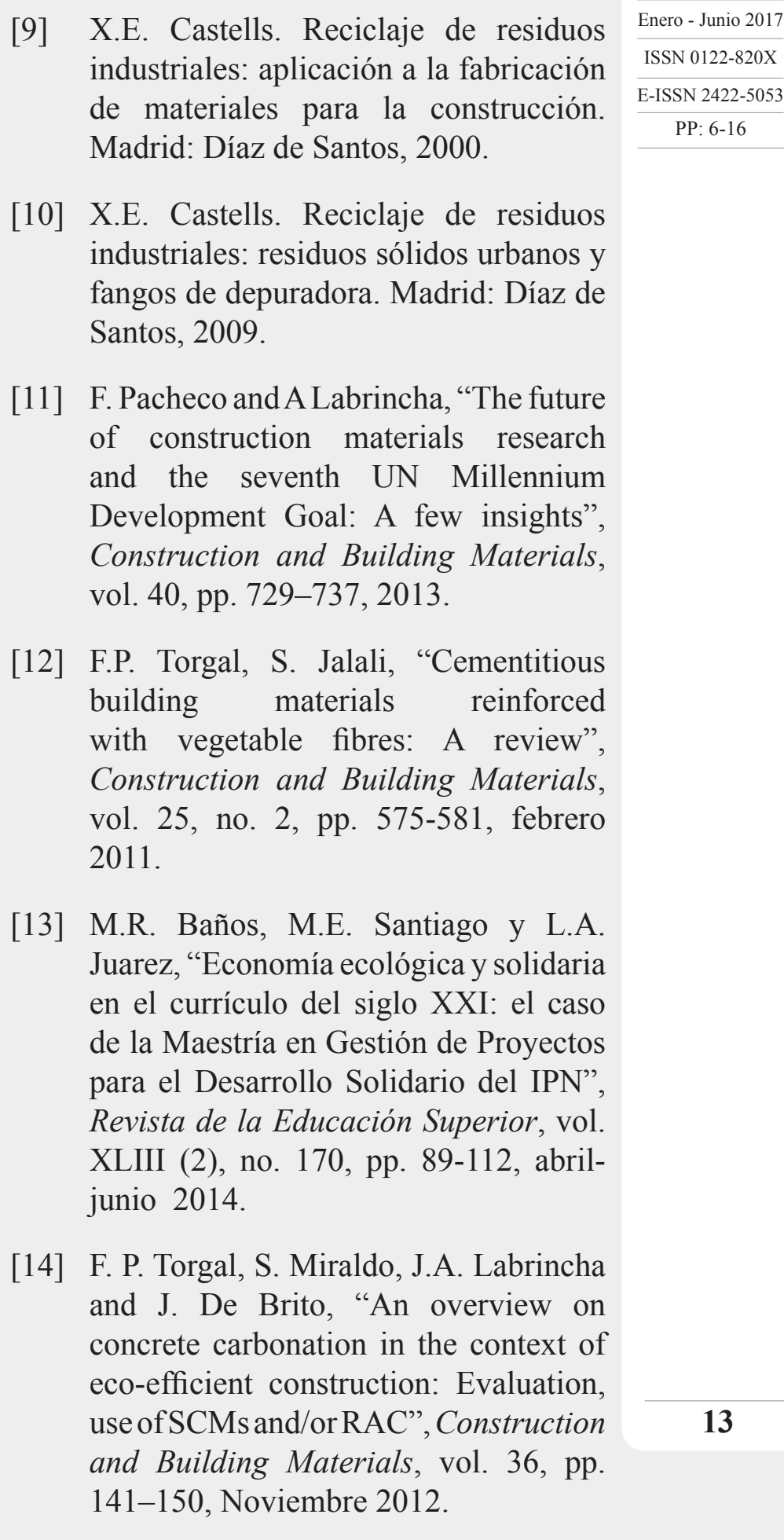

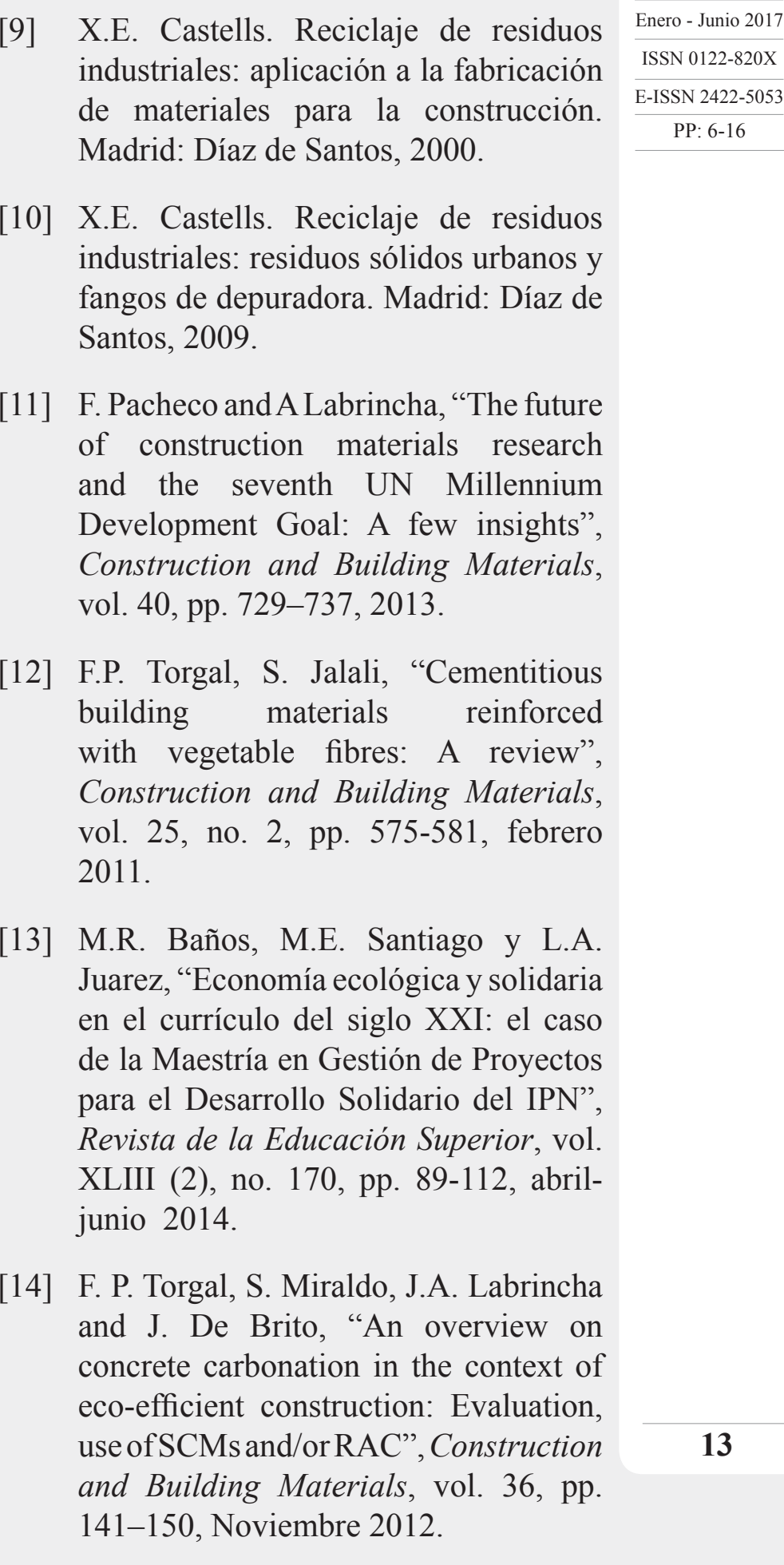

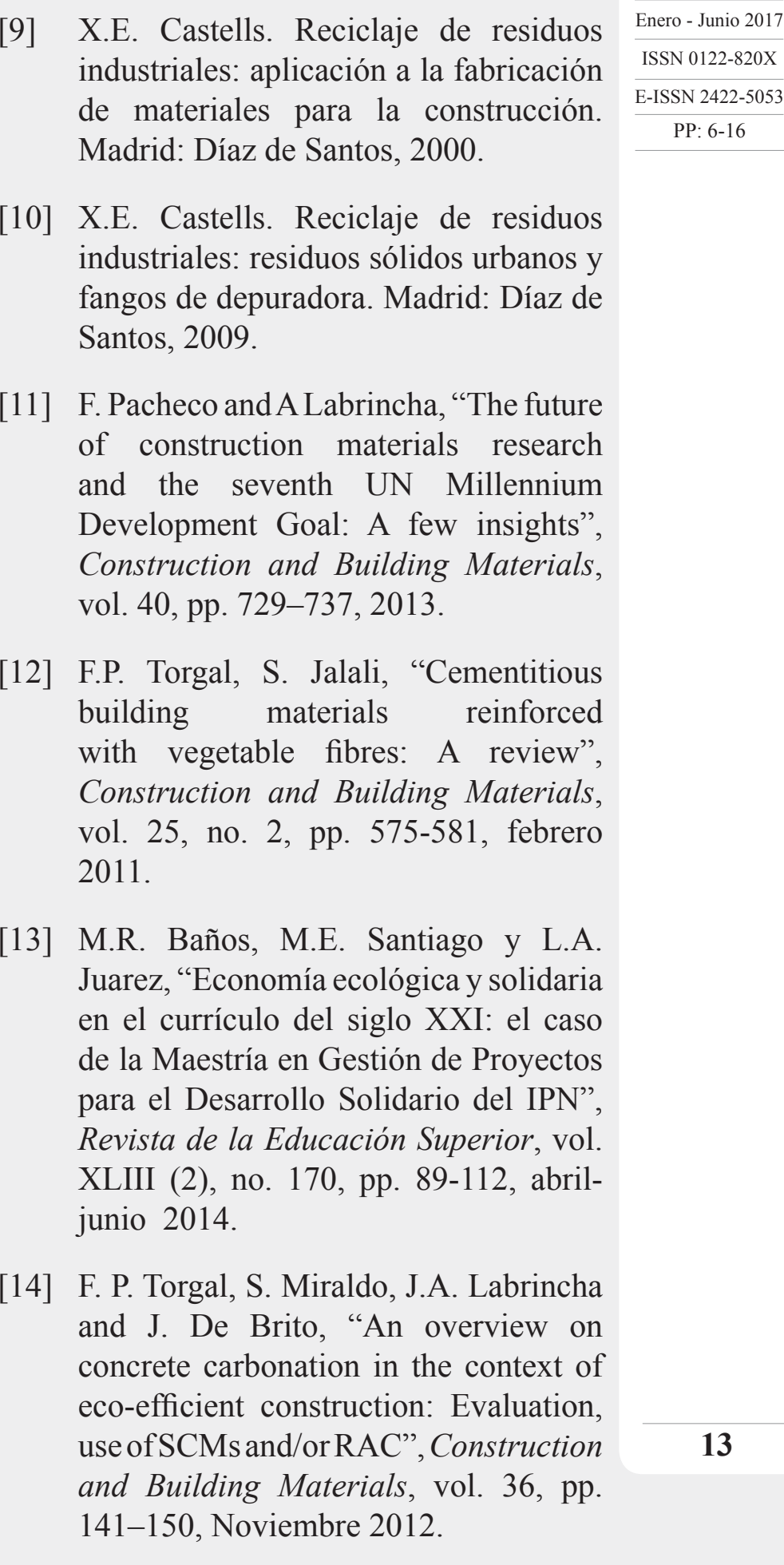

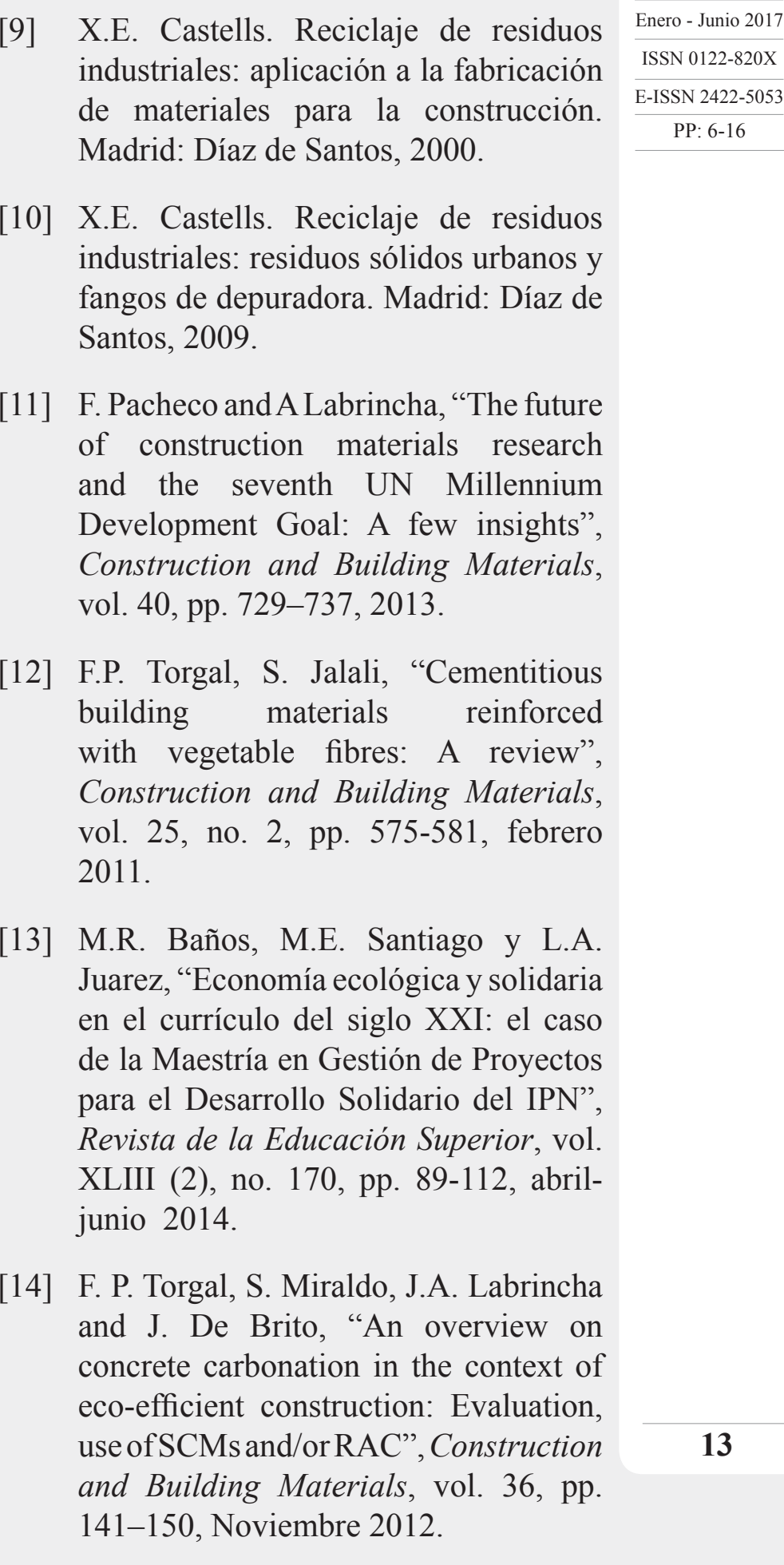

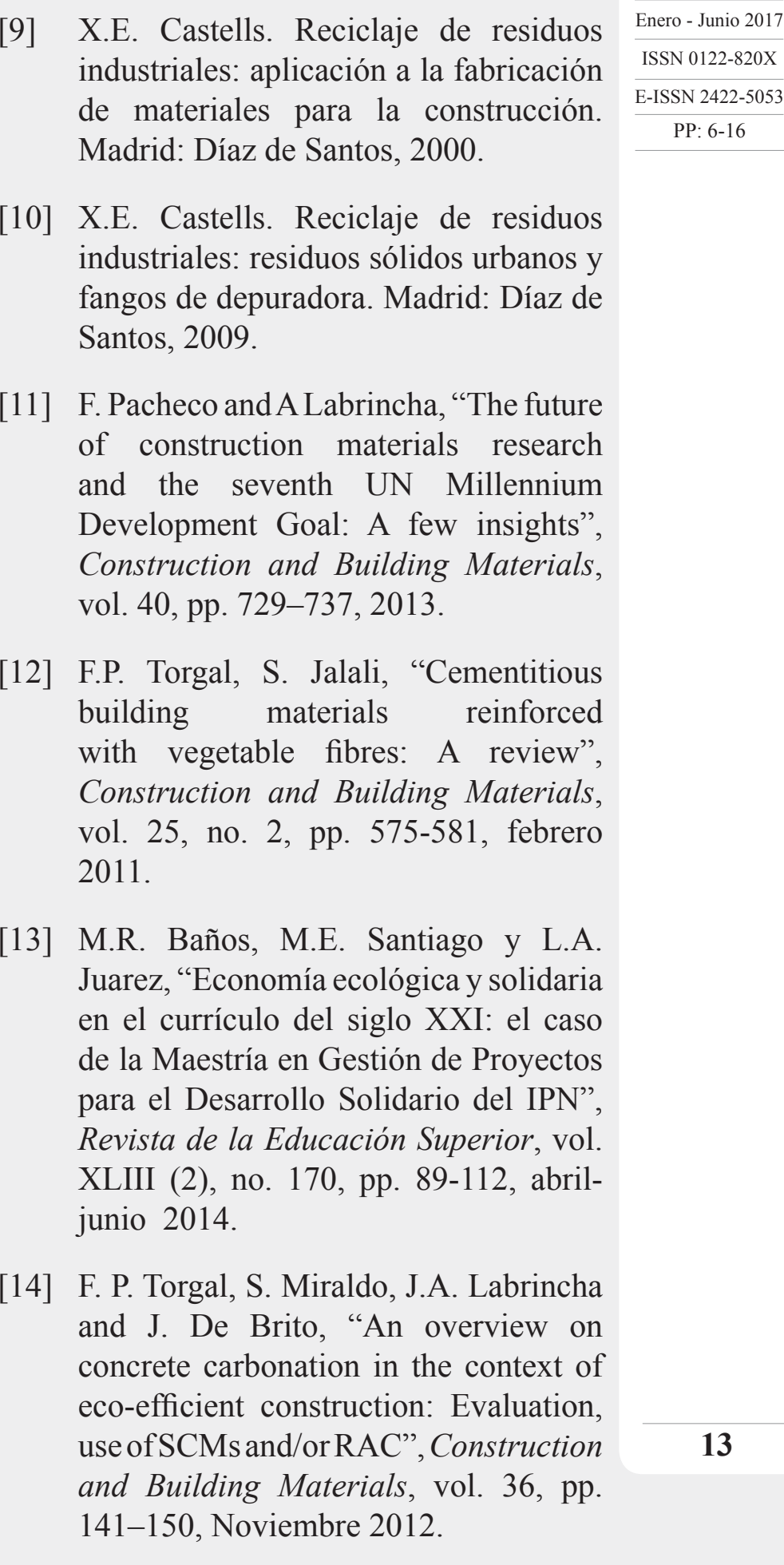

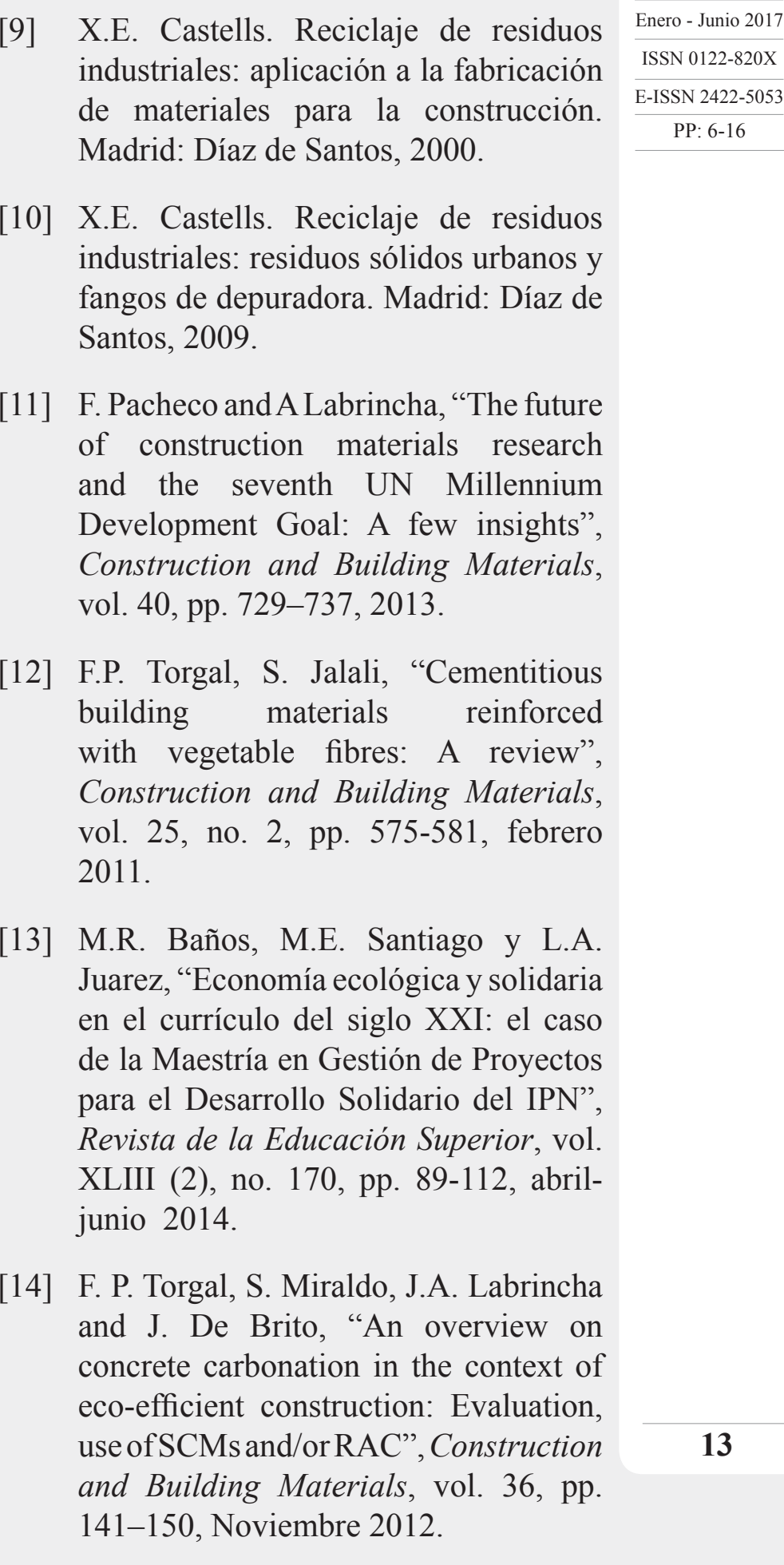

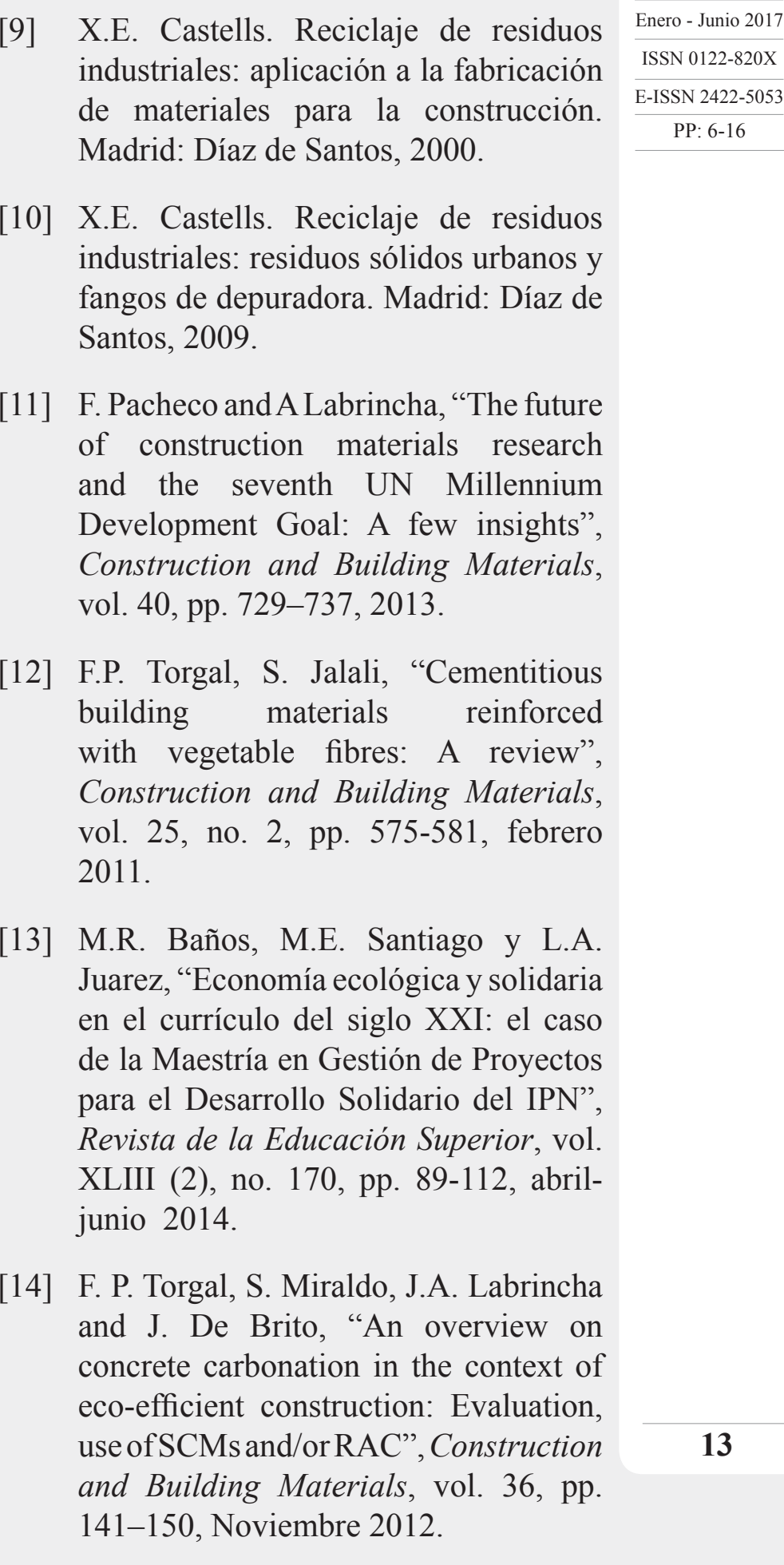

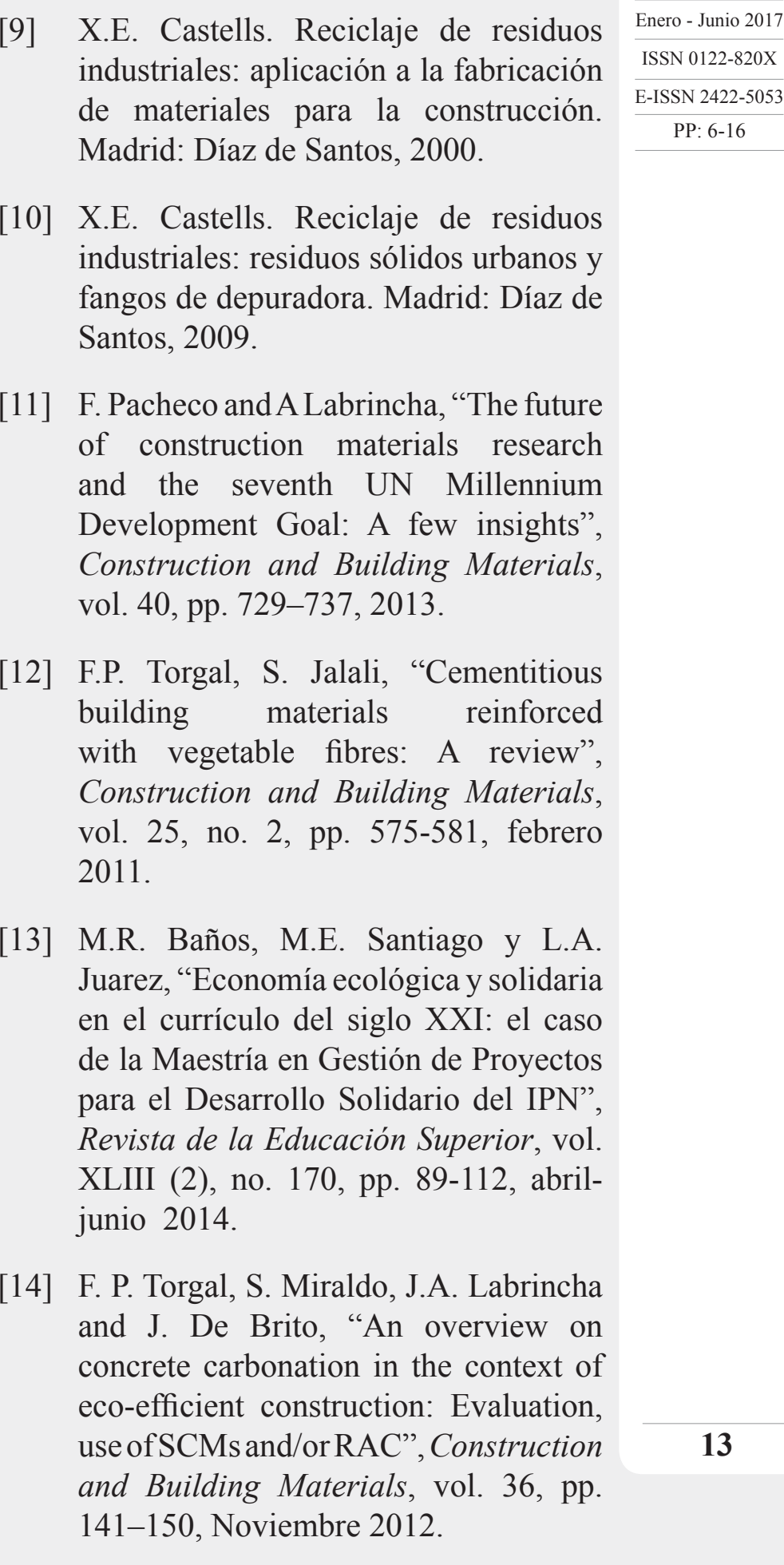

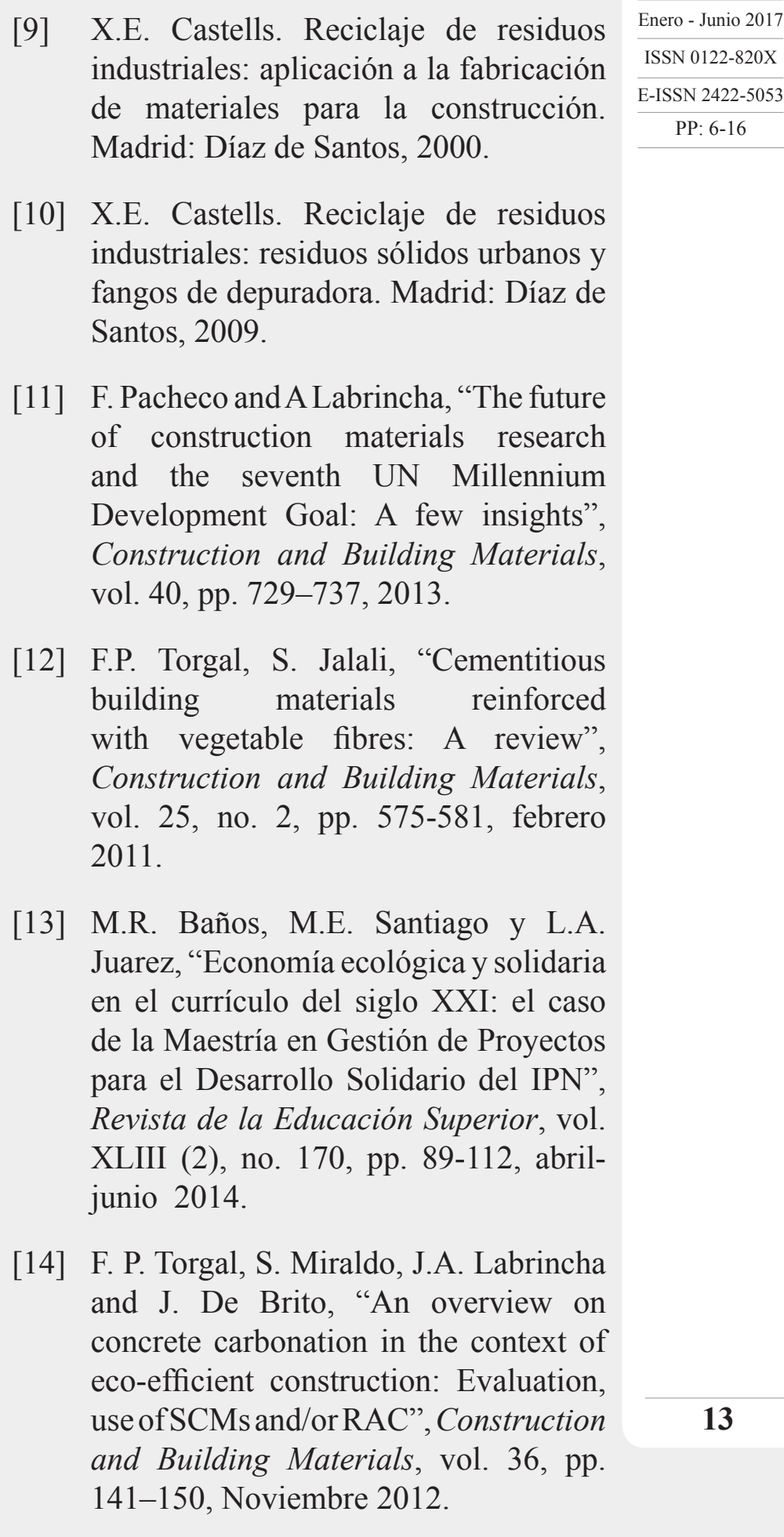

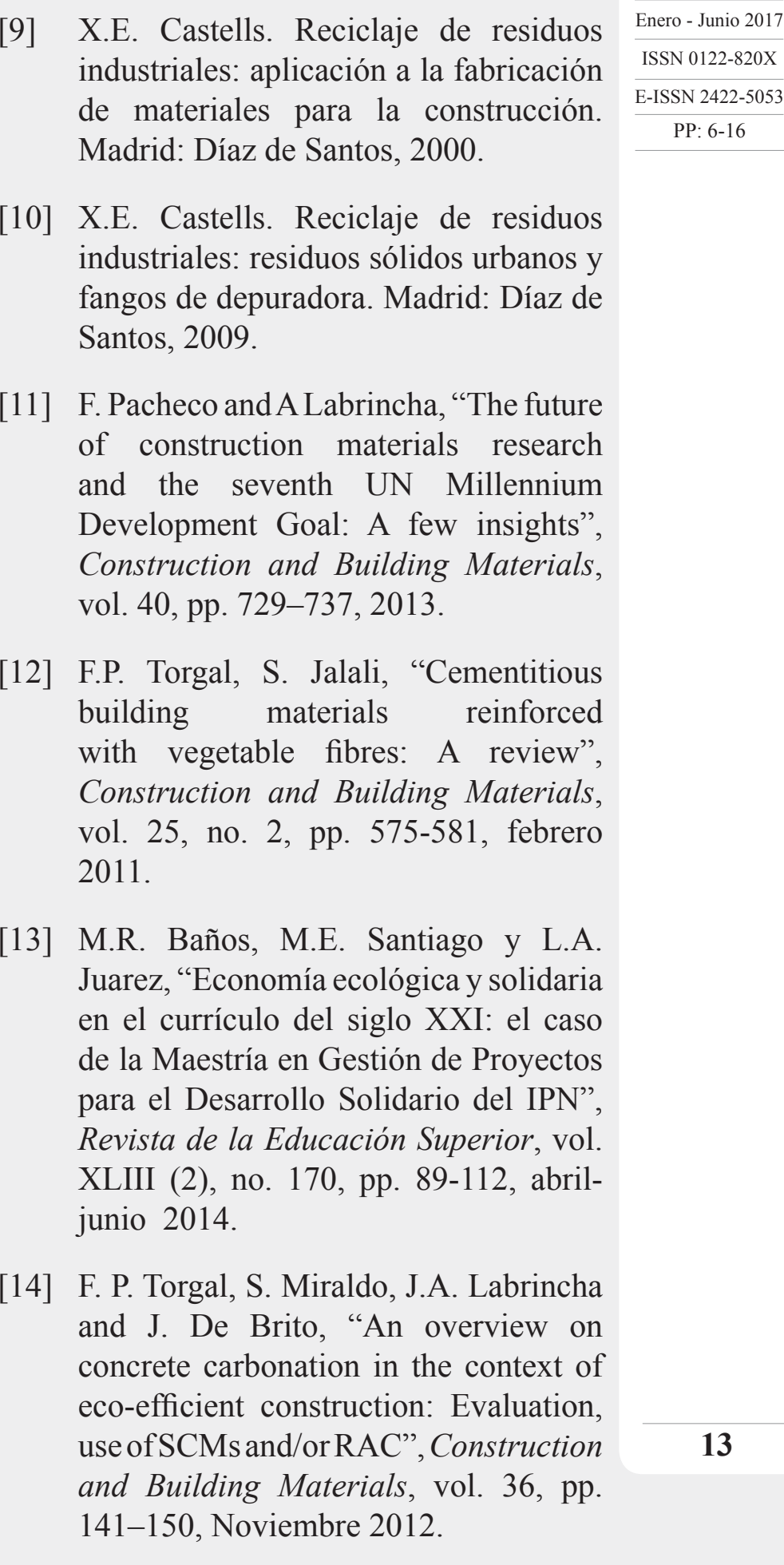

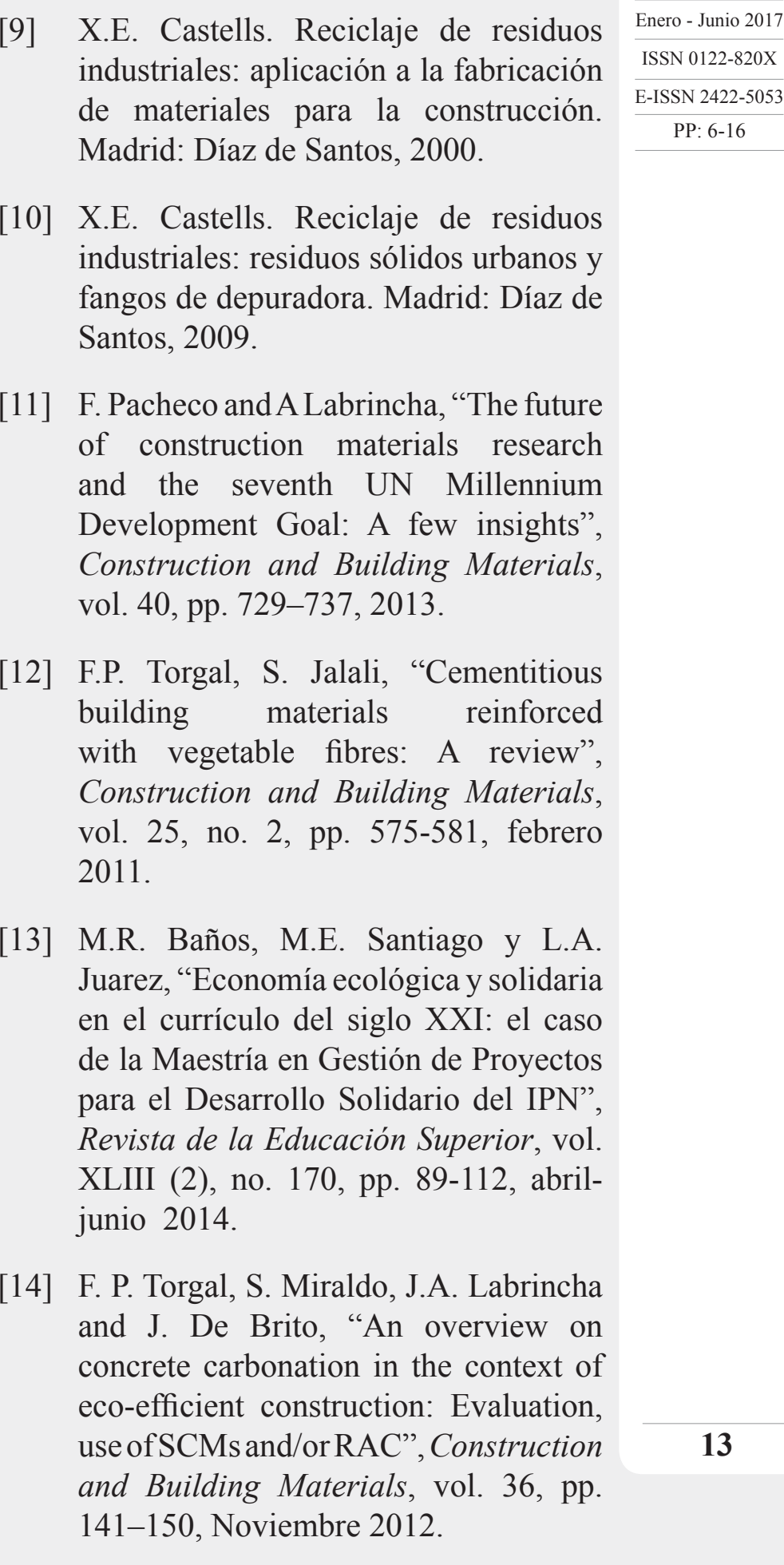

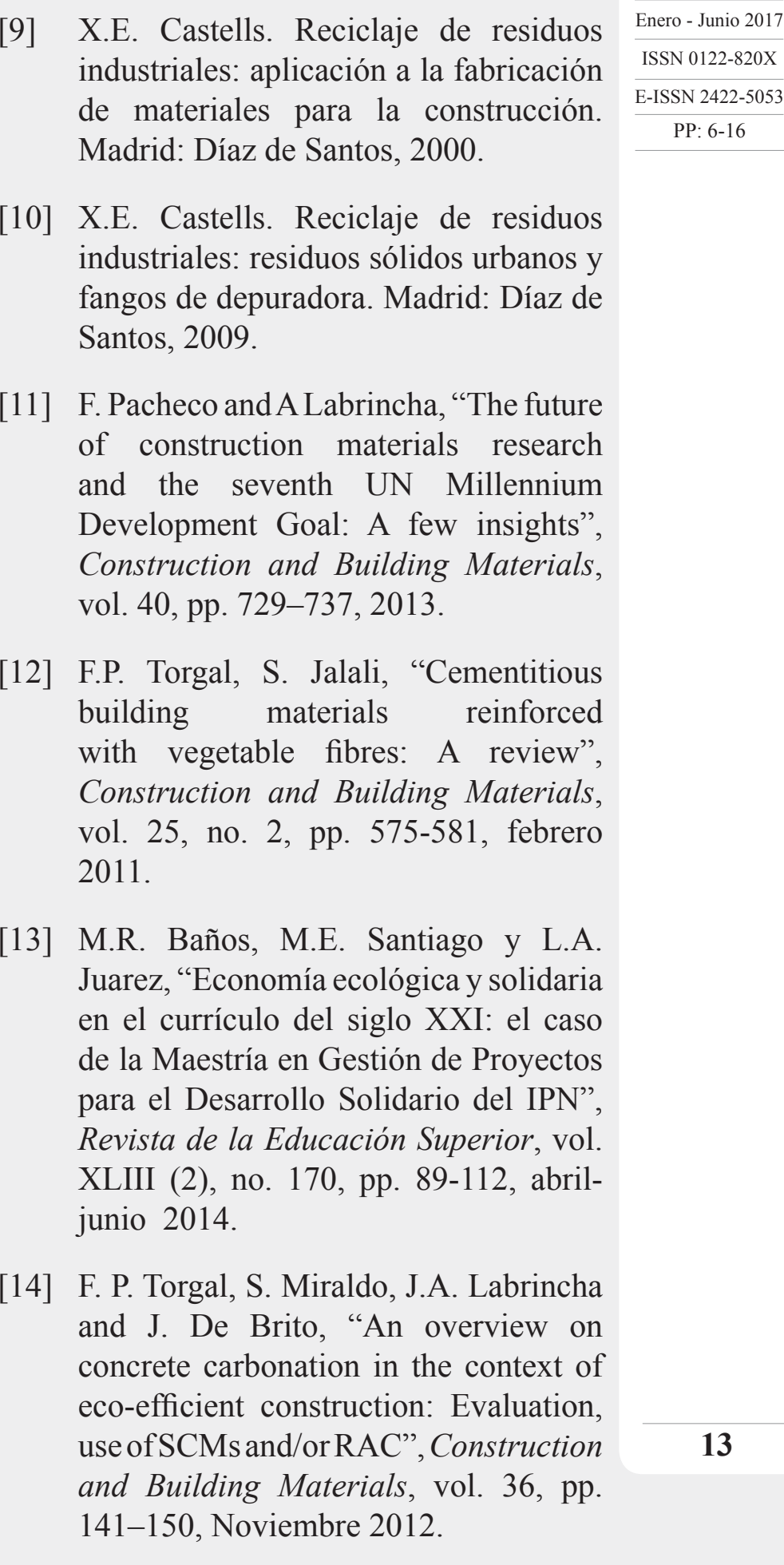

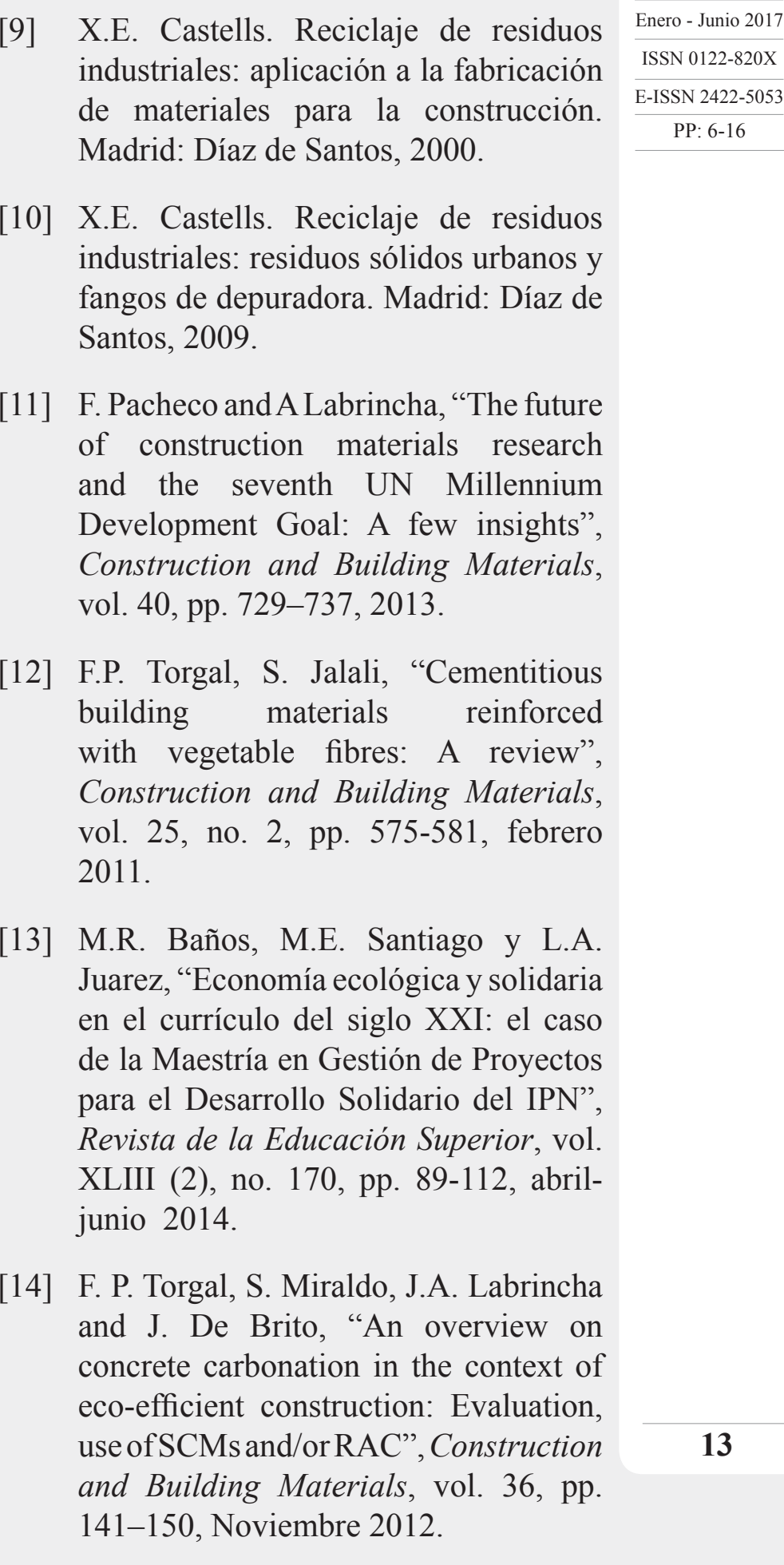

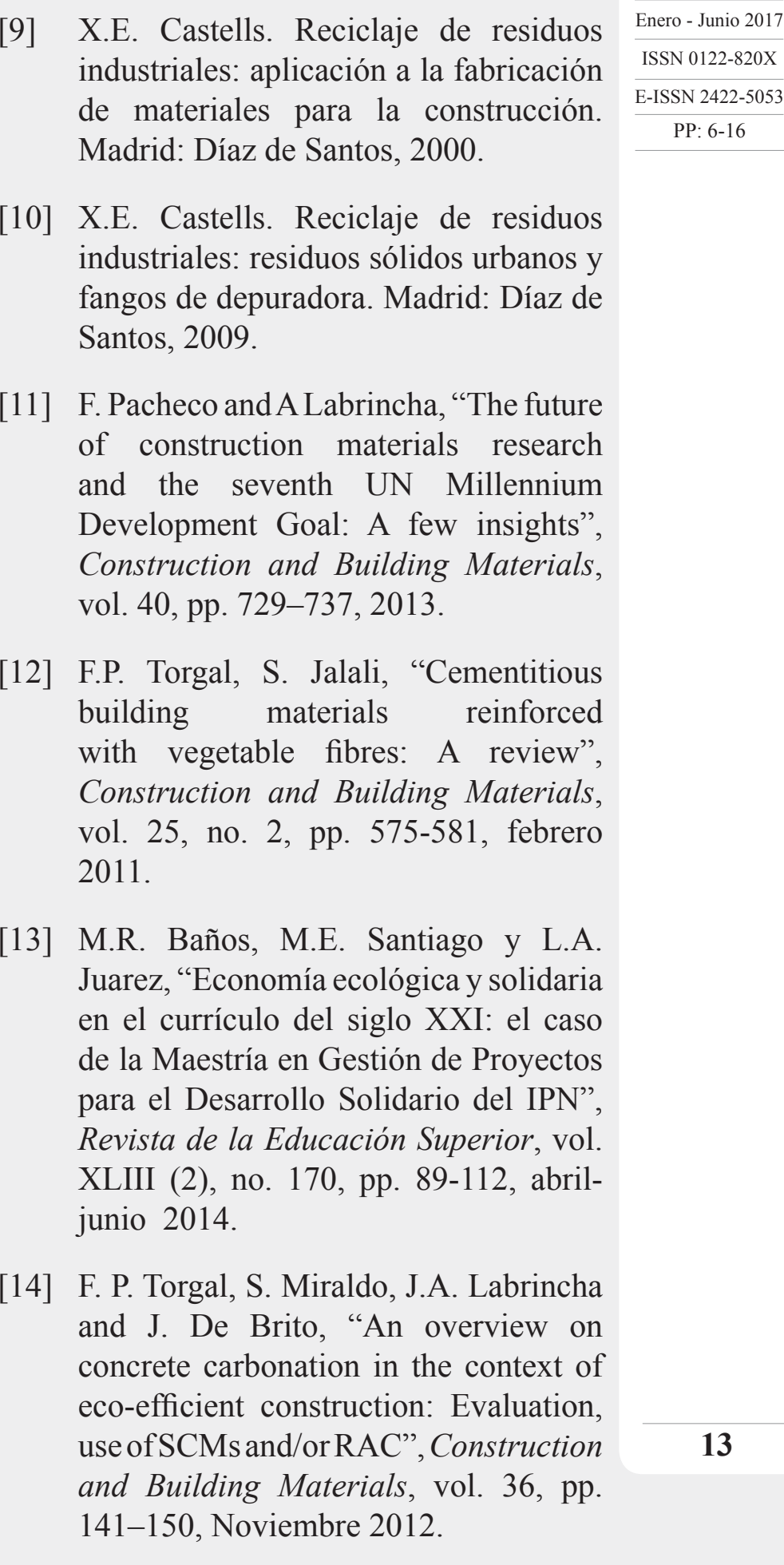

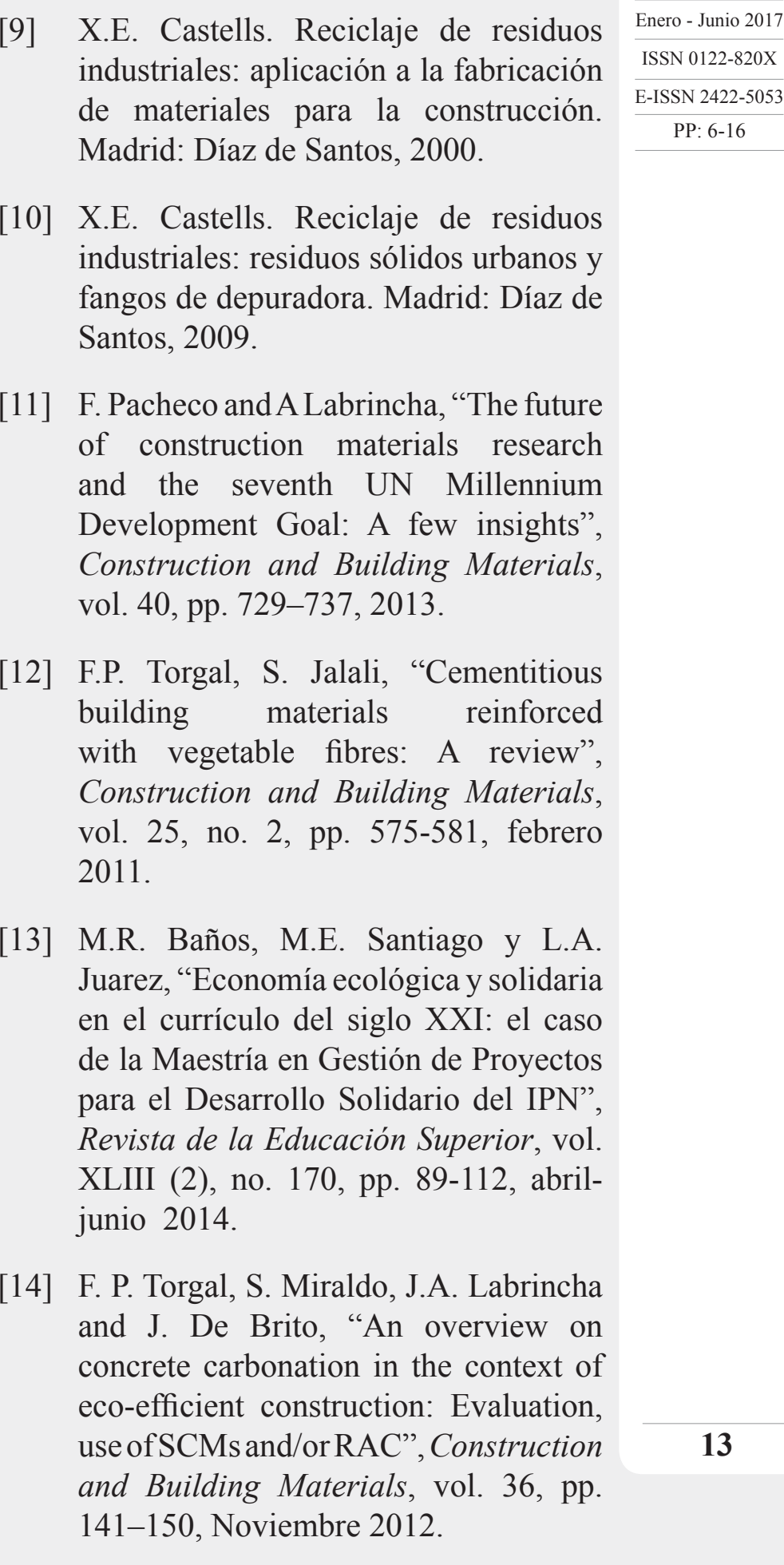

15] J. B. Hernández, T. Lópezy C. Menchaca (Eds.). Materiales Sustentables y Reciclados en la Construcción. Barcelona, España: OmniaScience, 2015.

[16] B. Suhendro, "Toward Green Concrete for Better Sustainable Environment", 
[17] S.F. Korenkova and Y.V. Sidorenko, "Improving Durability of Cement Composite Materials", Procedia Engineering, vol. 111, pp. 420-424, 2015.

[18] K. Renga, D. Thevaneyan, B.M. Azam and N. Kuganeswaran, "Repair of Deteriorating Pavement Using Recycle Concrete Materials", Procedia Engineering, vol. 142, pp. 371 - 382, 2016.

[19] N.M. Patil and V.G. Khurd, "Utilization of Waste Plastic in Road Construction" International Journal of Inventive Engineering and Sciences (IJIES), vol. 3, no. 9, pp. 25-28, August 2015.

[20] R.S. Chhabra and S. Marik, "A Review Literature On The Use Of Waste Plastics And Waste Rubber Tyres In Pavement", International Journal of Core Engineering \& Management (IJCEM), vol. 1, no. 1, pp.1-5, abril 2014.

[21] A.B. de Melo y E.P. Silva, "Bloques de hormigón ligero con áridos reciclados de EVA: una contribución a la eficiencia térmica de paredes exteriores de edificios", Materiales de Construcción, vol. 63 , no. 312, pp. 479-495, octubrediciembre 2013. materiales de construcción en el paradigma de la economía circular
Transportation Research Procedia, vol. 14, pp. 3512-3518, 2016.

[24] J.J. Zavala, F.J. García, H. Carrillo, J. Navarrete, J.B. Hernández y T. López. Uso de residuos agroindustriales para la estabilización de adobes. En G. Martinez, J.B. Hernández, T. López y C. Menchaca (Eds.). Materiales Sustentables y Reciclados en la Construcción. Barcelona, España: OmniaScience, 2015, pp. 11-30.

[25] F.P. Torgal and S. Jalali, "Earth construction: Lessons from the past for future eco-efficient construction", Construction and Building Materials, vol. 29, p.p. 512-519, abril 2012.

[26] S. Viveros, I. Rivera, A. Alvarez C. Menchaca y J. Uruchurcu. Uso de Materiales Reiclados para el Mejoramiento de las Propiedades Mecánicas y Electroquímicas de Concreto Reforzado En G. Martinez, J. B. Hernández, T. López y C. Menchaca (Eds.). Materiales Sustentables y Reciclados en la Construcción. Barcelona, España: OmniaScience, 2015, pp. 61-71.

[27] Z. Zhanga, P. Wanga and J. Wua, "Dynamic Mechanical Properties of EVA Polymer-Modified Cement Paste at Early Age", Physics Procedia, vol. 25, pp. $305-310,2012$.

[28] H.S. Müller, "Design and Properties of Sustainable Concrete", Procedia Engineering, vol. 95, pp. 290-304, 2014.

[29] A. Kumar, P. Kumar and G.D Ransinchung, "Use of Various Agricultural and Industrial Waste Materials in Road Construction", Procedia - Social and Behavioral Sciences, vol. 104, no. 2, pp. 264-273, diciembre 2013. 
[30] C.G. Argis. Estudio de la utilización de las cenizas de cenicero de centrales termoeléctricas de carbón, como adición al cemento portland, análisis comparativo con las cenizas volantes. Tesis doctoral, 2014. [En Línea] Disponible en: http://oa.upm. es/30411/1/Cristina_Argiz_Lucio.pdf

[31] P. Camargo, A.M. Pereira, J.L. Akasaki, C.F. Fioriti, J. Payá y J.L Pinheiro, "Rendimiento de morteros producidos con la incorporación de ceniza de bagazo de caña de azúcar", Revista ingeniería de construcción, vol. 29, no. 2, pp. 187-199, 2014.

[32] D.V. Vidal, Torres, R. Mejia y L.O. Gonzalez, "Estudio comparativo de cenizas de bagazo de caña como adición puzolánica", Revista Colombiana de Materiales, Edición especial artículos cortos, no. 5, pp. 13-18, 2014.

[33] T. Serrano, M.V. Borrachero y J.M. Monzó. Paya, "Morteros aligerados con cascarilla de arroz: diseño de mezclas y evaluación de propiedades", DYNA, vol, 79, no. 175, 2012.

[34] N.M.Al-Akhras, "Performance of olive waste ash concrete exposed to alkalisilica reaction", Structural Concrete, vol. 13 , no. 4, pp. 221-226, diciembre 2012

[35] Grupo de Investigación en Tecnología Cerámica GITEC, "Evaluación de los cambios en las propiedades térmicas y mecánicas del bloque \#5 fabricado en la región, según las mezclas entre arcillas y residuos industriales", Universidad Francisco de Paula Santander, Facultad de Ciencias Básicas, Departamento de Química, 2013.

[36] D. Eliche, C. Martínez, M.L. Martínez, M.T. Cotes, L. Pérez, N. Cruz and F.A. Corpas, "The use of different forms of waste in the manufacture of ceramic bricks", Applied Clay Science, vol. 52, pp. 270-276, 2011.

[37] M.A. Schettino and J.N. Holanda, "Characterization of sugarcane bagasse ash waste for Its Use in Ceramic Floor Tile", Procedia Materials Science, vol. 8, pp. 190 - 196, 2015.

[38] L. Pérez, D. Eliche, F.J. Iglesias, C. Martínez and F.A. Corpas, "Recycling of ash from biomass incinerator in clay matrix to produce ceramic bricks", Journal of Environmental Management, vol. 95, pp. S349-S354, 2012.

[39] N.U. Kockal, "Utilisation of different types of coal fly ash in the production of ceramic tiles", Boletín de la Sociedad Española de Cerámica y Vidrio, vol. 51, no. 5, pp. 297-304, Septiembre-Octubre 2012 .

[40] C. Martínez, D. Eliche, L. Pérez, F. J. Iglesias and F.A. Corpas, "Sludge valorization from wastewater treatment plant to its application on the ceramic industry", Journal of Environmental Management, vol. 95, pp. S343-S348, 2012.

[41] C. Martínez, T. Cotes and F.A. Corpas, "Recovering wastes from the paper industry: Development of ceramic materials, Fuel Processing Technology", Fuel Processing Technology, vol. 103, pp. 117-124, 2012.

0122-820X

SN 2422-5053

6-16 
[44] L. Pérez, F.A. Corpas, S. Martínez, R. Artiaga and J. Pascual, "Manufacturing new ceramic materials from clay and red mud derived from the aluminium industry", Construction and Building Materials, vol. 35, pp. 656-665, 2012.

[45] N. Quarantaa, G. Pelozoa and O. Díaza, "Evaluation of Different Steel Wastes and its Influence in Ceramic Bricks Shaping by Extrusion", Procedia Materials Science, vol. 8, pp. $236-$ 244, 2015.

[46] J. Sánchez, J. Duran y Y.X. Pinto. "Estudio de factibilidad técnica y económica orientado a la utilización de Residuos de tierra diatomácea y lodo de cal resultantes de la industria Cervecera en la fabricación de bloques de gres", Respuestas, vol. 7, no. 1, pp.3-8, 2002.

[47] D. Eliche, F.J. Iglesias, L. Pérez and F.A. Corpas, "Replacement of the mixing fresh water by wastewater olive oil extraction in the extrusion of ceramic bricks", Construction and Building Materials, vol. 68, pp. 659-666, 2014.

[48] A. Guzman, S. Delvasto y E. Sanchez, V. Amigó, "Cenizas del tamo de arroz como substituto del feldespato en la fabricación de cerámica blanca", Boletín de la Sociedad Española de Cerámica y Vidrio, vol. 52, no. 1, pp. 25-30, Enero-Febrero 2013.

[49] M. Doynova, T. Dimitrovb and S.Kozhukharove, "Alternative technological approach for synthesis of ceramic pigments by waste materials recycling", Boletín de la Sociedad Española de Cerámica y Vidrio, vol. 55, pp. 63-70, 2016.
[50] Q. Ren, "Circular Economy Action Programs and Countermeasures for Small and Medium-sized Resourcebased Cities of China-Case Study of Zibo City of Shandong Province", Energy Procedia, vol. 5, pp. 21832188, 2011.

[51] D.A.R George, B.C Ling and Y. Chen, "A circular economy model of economic growth", Environmental Modeling \& Software, vol. 73, pp.60-63, 2015.

[52] L. Reh, "Process Engineering in circular economy", Particuology, vol. 1, no. 2 , pp.119-133, 2013. 